\title{
The Thermal Electrolytic Production of Mg from MgO: A discussion of the electrochemical reaction kinetics and requisite mass transport processes
}

\author{
N. Leonard", M. Korenko, ${ }^{1}$, C. Larson ${ }^{1}$, K. Blood ${ }^{1}$, L. J. Venstrom¹, S. Nudehi ${ }^{1}$, S. \\ Duncan', R. Diver ${ }^{2}$, F. Simko ${ }^{3}$, J. Priscak ${ }^{3}$, J. Schoer ${ }^{1}$, P. T. Kissinger ${ }^{4}$, and R. \\ Palumbo ${ }^{1 \ddagger}$ \\ ${ }^{1}$ Valparaiso University, 1900 Chapel Drive, Valparaiso, Indiana, 46383 USA \\ ${ }^{2}$ Diver Solar LLC, 1112 Monte Largo NE, Albuquerque, New Mexico, 87123 USA \\ ${ }^{3}$ Institute of Inorganic Chemistry, Slovak Academy of Sciences, Dubravska cesta 9, Bratislava, 84536 \\ Slovakia \\ ${ }^{4}$ Purdue University, 610 Purdue Mall, West Lafayette, Indiana, 47907 USA \\ ‡Author for correspondence: Robert.Palumbo@valpo.edu
}

\begin{abstract}
We examined the kinetic and transport processes involved in $\mathrm{Mg}$ production from $\mathrm{MgO}$ via electrolysis at ca $1250 \mathrm{~K}$ with in a eutectic mixture of $\mathrm{MgF}_{2}-\mathrm{CaF}_{2}$, using a Mo cathode, and carbon anode. Exchange current densities, transfer coefficients, and diffusion coefficients of the electroactive species were established using a combination of cyclic and linear sweep voltammetry, chronoamperometry and electrochemical impedance spectroscopy. The cathode kinetics are described by a concentration dependent Butler-Volmer equation. The exchange current density and cathodic transfer coefficient are $11 \pm 4 \mathrm{~A} \mathrm{~cm}^{-2}$ and $0.5 \pm 0.12$ respectively. The kinetics of the anode are described by two Tafel equations: at an overvoltage below $0.4 \mathrm{~V}$, the exchange current density is $0.81 \pm 0.2 \mathrm{~mA} \mathrm{~cm}^{-2}$ with an anodic transfer coefficient of $0.5 \pm$ 0.1 ; above $0.4 \mathrm{~V}$ overvoltage the values are $0.14 \pm 0.05 \mathrm{~mA} \mathrm{~cm}^{-2}$ and $0.7 \pm 0.2$ respectively. The diffusion coefficients of the electroactive species are $D\left(\mathrm{Mg}^{2+}\right)=5.2 \pm 0.6 \mathrm{E}-5 \mathrm{~cm}^{2} \mathrm{~s}^{-1}$ and $D\left(\mathrm{Mg}_{2} \mathrm{OF}_{4}^{2-}\right)=7.2 \pm 0.2 \mathrm{E}-6 \mathrm{~cm}^{2} \mathrm{~s}^{-1}$. The ionic conductivity of the electrolyte is ca $2.6 \mathrm{~S} \mathrm{~cm}^{-1}$.
\end{abstract}


A 3D finite element model of a simple cell geometry incorporating these kinetic and transport parameters suggest that up to $27 \%$ of the energy required to drive the electrolysis reaction can be supplied thermally for a current density of $0.5 \mathrm{~A} \mathrm{~cm}^{-2}$, enabling a reduction in operating cost if the thermal energy is substituted for valuable electric work.

Keywords: Magnesium electrolysis from MgO, Solar thermal electrochemistry, Molten salts, Voltammetry, Chronoamperometry, Electrochemical Impedance Spectroscopy

\section{Introduction}

\subsection{Motivation for the Study}

We are developing an electrochemical-thermal process for the efficient production of magnesium $(\mathrm{Mg})$ from magnesium oxide $(\mathrm{MgO})$ that operates between 1200 and 1300 $\mathrm{K}$. Magnesium is produced in the process in the following electrochemical reaction:

$$
\mathrm{MgO}(\text { diss })+0.5 \mathrm{C}(\mathrm{s}) \rightarrow \mathrm{Mg}(\mathrm{l})+0.5 \mathrm{CO}_{2}(\mathrm{~g})
$$

The feedstock $\mathrm{MgO}$ is dissolved (diss) in a molten fluoride salt (eutectic mixture of $\mathrm{MgF}_{2}$ - $\left.\mathrm{CaF}_{2}\right)$ and electrolyzed to liquid $\mathrm{Mg}(\mathrm{l})$ and gaseous $\mathrm{CO}_{2}(\mathrm{~g})$. The $\mathrm{Mg}(\mathrm{l})$ forms at a cathode and the $\mathrm{CO}_{2}(\mathrm{~g})$ forms at a consumable solid carbon anode $\mathrm{C}(\mathrm{s})$. This approach has the potential to reduce capital and operating costs and mitigate the environmental impact of primary $\mathrm{Mg}$ production compared to the conventional $\mathrm{MgCl}_{2}$ electrolysis process and thermal Pidgeon processes. It reduces cost by simplifying the preparation of the $\mathrm{Mg}$ feedstock, replacing the dehydration and chlorination of brines to produce $\mathrm{MgCl}_{2}$ for $\mathrm{MgCl}_{2}$ electrolysis with a simpler calcination step to produce $\mathrm{MgO}$. It also theoretically uses $30 \%$ less energy than the thermal reduction Pidgeon processes 
(Palumbo et al., 2015), which reduces $\mathrm{CO}_{2}$ emissions and operating cost. Operating costs can be further reduced by substituting a fraction of the electrical energy required to produce $\mathrm{Mg}$ from $\mathrm{MgO}$ with thermal energy provided via either natural gas combustion or concentrated solar energy. In the latter case, there is no fuel cost for the thermal energy input, and in the former, natural gas costs, at most, 3 times less than electricity purchased from a utility.

From a commercialization perspective, the process has significance: it may be an ecoeconomic route to $\mathrm{Mg}$ production. But we also see the process as archetypical for producing metals from their oxides with both thermal and electric input, an idea which to our knowledge, was first articulated by Edward A. Fletcher from the University of Minnesota while launching the first US high temperature solar thermal chemistry research program in the late 1970's (Fletcher and Noring, 1983; Fletcher et al., 1985; Palumbo and Fletcher, 1988; Parks et al., 1988). We dedicate this study to him.

Using the $1^{\text {st }}$ and $2^{\text {nd }}$ Laws of Thermodynamics, he argued that the decomposition of $\mathrm{Al}_{2} \mathrm{O}_{3}, \mathrm{MgO}, \mathrm{TiO}_{2}, \mathrm{ZnO}$, and others can be described generically by Fig. 1. The total energy required for the production of the metal from its oxide with carbon as a reactant is $\Delta H_{r x n}$. Supplying this amount of energy is necessary, but not a sufficient condition. At least $\Delta G_{r x n}$ must be supplied as electric work in order to effect the transformation. Figure 1 illustrates that as the temperature of the reaction increases, one can substitute more and more thermal process energy for valuable electric work. To our knowledge no industrial electrolysis process takes advantage of this thermodynamic fact. Rather, all of the required energy is supplied as electric work. 


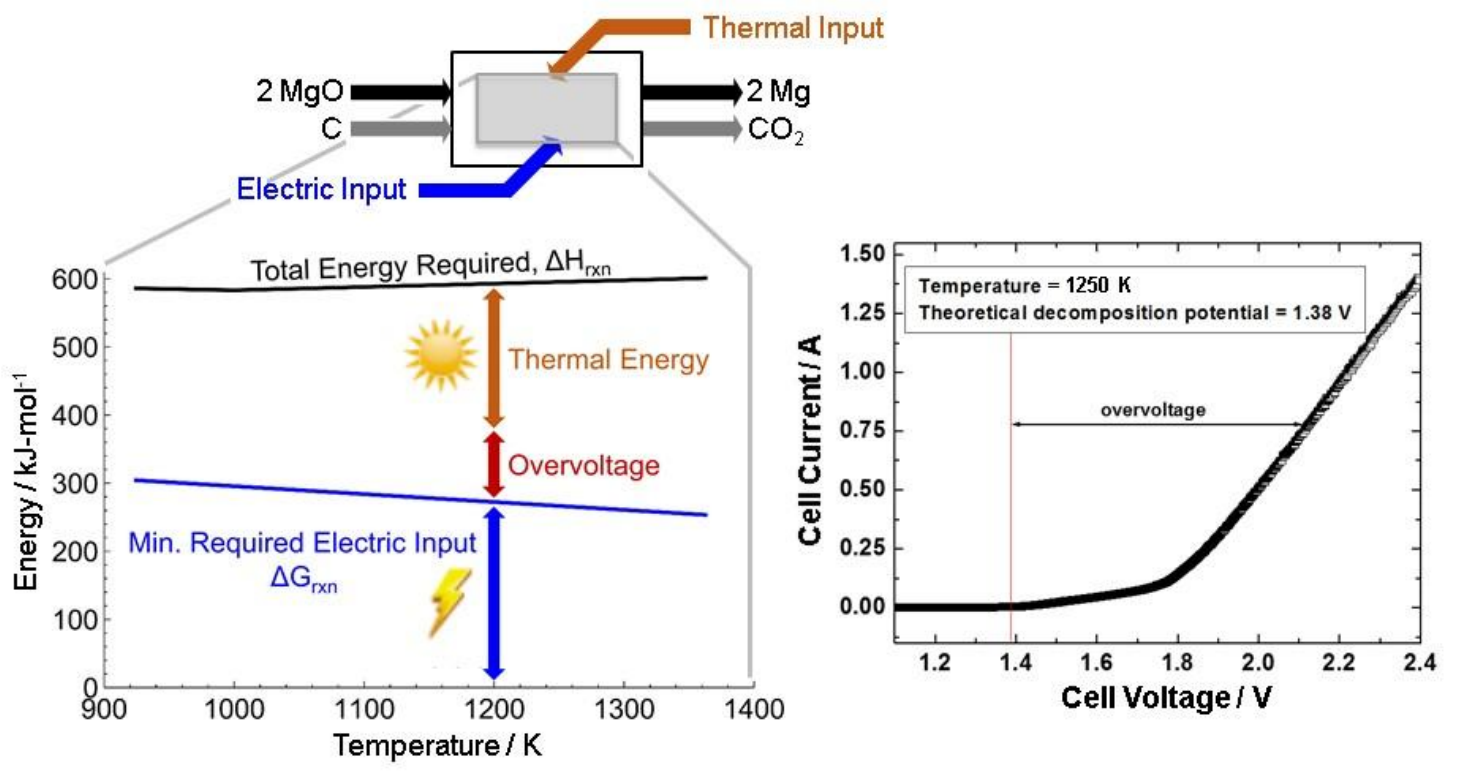

Fig. 1. Schematic showing the concept of the process: driving the electrochemical reaction with a thermal and electrical input. The thermal input is maximized by minimizing the overvoltage. Also shown is current as a function of cell potential; Electrolyte: $\left(\mathrm{MgF}_{2}-\mathrm{CaF}_{2}\right)_{\mathrm{EUT}}-\mathrm{MgO}$ (sat), cathode: Mo, anode: graphite.The overvoltage is defined as the voltage difference between a data point and the vertical line situated at circa $1.4 \mathrm{~V}$.

In this paper, we describe our effort to develop the requisite engineering science to enable the production of $\mathrm{Mg}$ with a thermal input at as low an electrical input as nature will allow. We anticipate that the substitution of electric energy for thermal energy will lower the operating cost associated with $\mathrm{Mg}$ production. Part of this effort means learning to minimize the overvoltage depicted in Fig. 1, as the overvoltage limits the opportunity to substitute thermal process heat for electric work.

\subsection{The Components of the Overvoltage}


The overvoltage represents the electrical energy per coulomb above the thermodynamic minimum one must supply in order to overcome ohmic resistance, mass transfer resistance, and electron charge transfer resistances.

Fig. 1 graphically shows the consequence of these resistances on cell performance. If they did not exist, the vertical line emanating from the reaction's decomposition potential would be the current vs. applied voltage for the cell: at any desired production rate, the electrical energy input would be the minimum shown in Fig. 1. The distance in volts at a given current level from the vertical line to the experimental data is the overvoltage corresponding to a given current level. The larger this overvoltage for a given current or production rate, the smaller the gap between the required energy to drive the reaction and the electrical energy input. The smaller the gap, the less opportunity we have for substituting process heat for electric work.

The overvoltage is given by the following equation:

$$
\eta_{\text {cell }}=\eta_{\text {cathode }}+\eta_{\text {anode }}+I R
$$

The first two terms are set by the charge transfer kinetics at the cathode and anode coupled to the corresponding transport rate of the electro-active species. The last term is set by the specific conductance of our electrolyte as well as the electrical resistance in components that connect the power supply to the electrodes and the resistance of the electrodes themselves.

\subsection{A Possible Reaction Mechanism}

To help establish the requisite parameters that set the overvoltage for a desired current level, we postulated the following reaction steps: 
Disproportionation:

$2 \mathrm{MgF}_{2}(\mathrm{~s}) \rightarrow \mathrm{MgF}_{4}^{-2}$ (diss) $+\mathrm{Mg}^{2+}$ (diss)

$M g O(s)$ Dissolution reaction:

$\mathrm{MgF}_{4}^{-2}$ (diss) $+\mathrm{MgO}(\mathrm{s}) \rightarrow \mathrm{Mg}_{2} \mathrm{OF}_{4}{ }^{2-}$ (diss)

Global Anode electron transfer reaction:

$\mathrm{Mg}_{2} \mathrm{OF}_{4}{ }^{2-}$ (diss) $+0.5 \mathrm{C}(\mathrm{s}) \rightarrow 2 \mathrm{MgF}_{2}$ (diss) $+0.5 \mathrm{CO}_{2}(\mathrm{~g})+2 \mathrm{e}^{-}$

Global cathode electron transfer reaction:

$\mathrm{Mg}^{2+}($ diss $)+2 \mathrm{e}^{-} \rightarrow \mathrm{Mg}(\mathrm{l})$

The mechanism for reaction (6) has been postulated as the following:

$\mathrm{Mg}^{2+}$ (diss) $+\mathrm{e}^{-} \rightarrow \mathrm{Mg}^{+}$rate limiting

$\mathrm{Mg}^{+}+\mathrm{e}^{-} \rightarrow \mathrm{Mg}(\mathrm{l})$ very fast

The parenthesis on each species have the following meaning: (s) means the solid phase; (diss) means dissolved in liquid phase; (g) means gas phase; and (I) means liquid phase.

The concentration of the $\mathrm{Mg}_{2} \mathrm{OF}_{4}{ }^{2-}$ in reaction (4) was set to the solubility of $\mathrm{MgO}$ that we found and reported in Palumbo et al. (2015).

To know how to minimize the overvoltage through cell design, we need the fundamental kinetic and mass transport parameters. We used Linear Sweep and Cyclic Voltammetry (LSV and CV), Chronoamperometry, Chronopotentiometry, and Electrochemical 
Impedance Spectroscopy (EIS) to establish them. The conductance of our electrolyte was established also by traditional means: measuring the resistance of our electrolyte, $R_{\mathrm{e}}$, with EIS and establishing a cell constant, $C_{c}$. The conductance, $\sigma$ is then given by $\sigma=C_{c} R_{e}^{-1}$

\subsection{Framework for the Electrochemical Reaction Model}

We anticipated that the cathode-electrolyte interface potential is coupled to the concentration dependent form of the Butler-Volmer equation for redox equation (Bard and Faulkner, 2001). In this equation the oxidized species, $c_{0}$, is $\mathrm{Mg}^{2+}$ in solution $\left(c_{M g 2+}^{B}\right)$ and the reduced species is $\mathrm{Mg}(\mathrm{l})$;

$$
i=i_{o}\left[1 * \exp \left(\frac{\beta F \eta}{R T}\right)-\frac{C_{M g 2+}}{C_{M g 2+}^{B}} \exp \left(\frac{-\alpha F \eta}{R T}\right)\right]
$$

$i_{o}, \alpha$ and $\beta$ are the values we established as the cathode kinetic parameters. We further presumed that the mass transport of the electro-active species will be described by Fick's laws of diffusion:

$$
\frac{\partial C_{M g 2+}}{\partial t}=-D_{M g^{2+}} \nabla^{2} C_{o}=J
$$

where $J=0$, except at the cathode-electrolyte interface, where it is

$$
J=\frac{-i}{n F}
$$

$D_{M g^{2+}}$ is the diffusion coefficient we established for the electroactive species at the cathode.

We anticipated that the anode kinetics will be described by Tafel kinetics: 


$$
i=i_{0} \exp \left\langle\frac{\beta n F}{R T} \eta\right\rangle
$$

This description of the anode kinetics implies that the electron transfer rate is irreversible. We argue that invoking this assumption is reasonable given that the oxidation product $\mathrm{CO}_{2}$ is bubbling away from the anode making the reverse reduction reaction difficult. Furthermore we expect that the bubbling induces strong mixing near the anode thereby augmenting the transport of the electroactive species beyond that associated with diffusion. We discuss the significance of this nuance in our results section.

To the extent possible, we evaluate the reasonableness of our kinetic and mass transport values by comparing them to those reported in the kinetic and mass transfer literature, specifically those that emerged from the development of the $\mathrm{MgCl}_{2}$ electrolysis process as well as the engineering science literature of the Hall-Héroult process. As a further validity test of the experimental results, we installed the estimated transport variables into a 3-D finite element program that describes one of our simple cells. We compared the output of the program to that of measured cell current vs. applied potential data.

\section{The Experimental Set-Up}

\subsection{Electrochemical Kinetics}

\subsubsection{Cathode Studies}

For studying the cathode kinetics and corresponding mass transfer of the electro-active species, our working electrode was a Mo wire, circa $0.2 \mathrm{~cm}^{2}$. The graphite auxiliary electrode had a projected surface area of at least $4 \mathrm{~cm}^{2}$. As shown in Fig. 2, we had 
two Mo quasi reference electrodes, also circa $0.2 \mathrm{~cm}^{2}$. The electrolyte was an eutectic mixture of $\mathrm{CaF}_{2}-\mathrm{MgF}_{2}$ and at times this mixture was saturated (sat) with $\mathrm{MgO}$. The electrolyte reagents were purchased from Alfa Aesar. The reported purities are $99.5 \%$ $\mathrm{CaF}_{2}, 99 \% \mathrm{MgF}_{2}$, and $99.95 \% \mathrm{MgO}$. The anode was made from $99.95 \%$ pure isomolded graphite and purchased from the Graphite Store.

Some commentary on the electrolyte and the quasi reference electrodes is necessary. Because nearly 50 mole \% of our solvent contains our solute in the form of magnesium fluoride, $\mathrm{MgO}$ adds an insignificant contribution to the concentration of the cathode's electroactive species $\mathrm{Mg}^{2+}$. We thus presumed the concentration of $\mathrm{Mg}^{2+}$ to be that corresponding to reaction (3), i.e. we assumed complete disproportionation of the magnesium fluoride. For our work that concentration is $0.0096 \mathrm{~mol} \mathrm{~cm}^{-3}$. Here, two points are important. Firstly, we anticipated that adding $\mathrm{MgO}$ to our electrolyte could add confusion to data emerging from a kinetic study of $\mathrm{Mg}^{2+} \mathrm{Mg}$ : The auxiliary electrode is likely to first evolve $\mathrm{CO}_{2}$ and at more positive anode potentials, $\mathrm{CF}_{4}$, a change that maybe manifested as a second wave in the reduction/oxidation voltammograms for the working electrode. Thus in some of our studies, we used only the eutectic mixture of $\mathrm{CaF}_{2}-\mathrm{MgF}_{2}$.

Secondly, we began our experiments by first cleaning our solvent: we thermally and electrolytically drove out impurities such as adsorbed $\mathrm{H}_{2} \mathrm{O}$. In order to assess our success at purifying the solvent, we monitored the gases leaving the cell at the anode outlet with a Varian 490 micro-gas chromatograph, observing a rise and then drop in $\mathrm{H}_{2}$, and we monitored the drop in current during bulk electrolysis at potentials below those expected for our reaction. 
We used two Mo wires as our quasi reference electrodes. Wire 1 shown in Fig. 2 is connected to the cathode through our Gamry 3000 potentiostat. The potentiostat applies potential to the cathode with respect to this reference electrode. We used Mo wire 2 to partially validate the quasi reference nature of the Mo wire: As shown in Fig. 2, we monitor

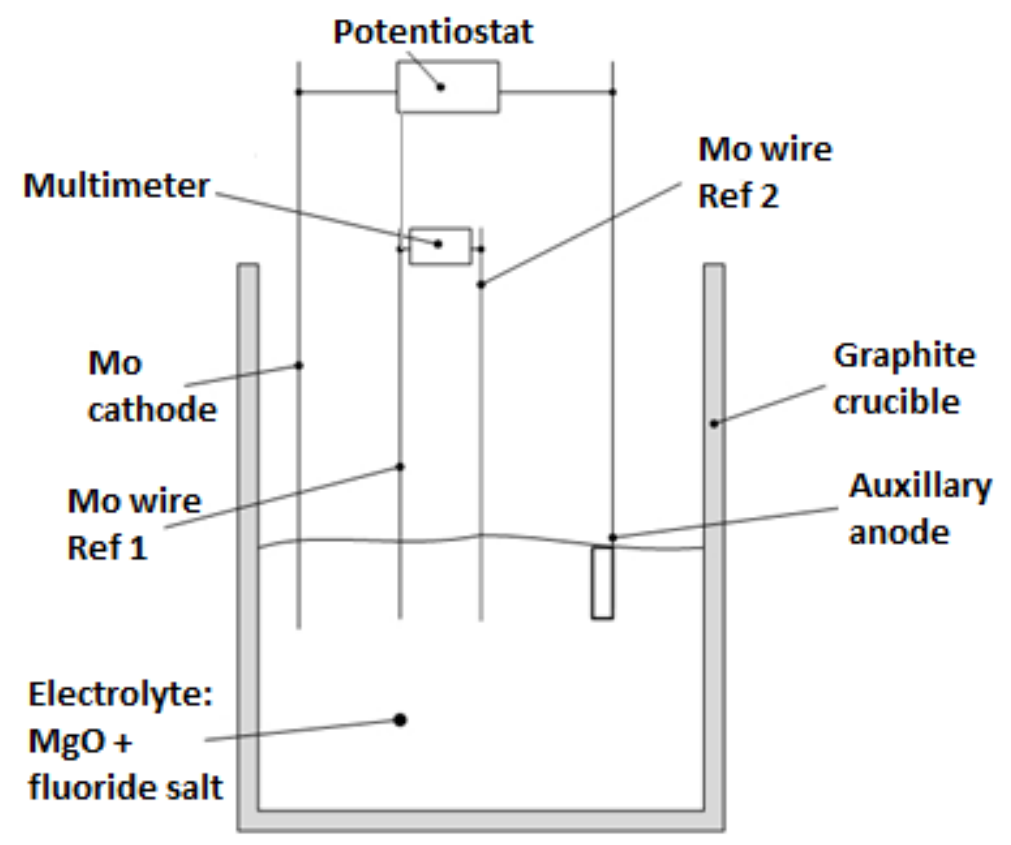

Fig. 2. Cell instrumented to validate quasi reference electrode and obtain thermodynamic information. The key features of the set-up: two reference electrodes and a multimeter confirming that there is no change in the interfacial potential at the reference electrodes as a potential change is applied between the working electrode and the electrode under investigation.

with a high impedance voltmeter the potential between the two reference electrodes in order to obtain experimental evidence that the potential difference between the Mo wire 1 and the electrolyte is not changing as the potentiostat changes the potential between the cathode and this quasi reference electrode. We found no measurable changes in potential between these wires at a scan rate as low as $1 \mathrm{mV} \mathrm{s}^{-1}$. 
In our Results section, we give further evidence for the validity of our quasi reference electrode, and we also illustrate how we were able to define electrochemical equilibrium and therefore an electrode overvoltage.

We established kinetic parameters (cathode and anode) from the multiple steady state and transient experimental methods, mentioned in the introduction. Each method offers a different approach for negotiating the presence of non-kinetic effects in the data. . We thus presume that reasonable agreement between different methods helps validate results. Furthermore, the scatter in the results between methods will give a first estimate of the uncertainty intervals for our results.

\subsubsection{Anode Studies}

The experimental set-up for the anode study was essentially that described above for the cathode. Of course the applied potential was supplied to the anode with respect to the Mo quasi reference electrode. Because the cathode became the auxiliary electrode, its surface area was increased to $1.7 \mathrm{~cm}^{2}$. The anode became the working electrode so its area was reduced to about $1 \mathrm{~cm}^{2}$. To ensure an electrolyte saturated with $\mathrm{MgO}$, three mole percent (10 times the solubility limit) was added to our eutectic mixture of $\mathrm{MgF}_{2}-\mathrm{CaF}_{2}$ (Palumbo et al., 2015). As with the cathode study, several electrochemical methods were used to probe the kinetics of the anode reaction.

\subsection{Conductance of the Electrolyte}

Our conductivity measurements were made with an apparatus and experimental method described in the literature. (Korenko et al, 2012; Fellner et al., 1993; Híveš et al., 1996; Kim and Sadoway, 1992; Wang et al., 1992) ). 
The essence of the method is based on electrochemical impedance spectroscopy. A conductivity cell with a known cell constant was stimulated with a sinusoidal signal with an amplitude of $10 \mathrm{mV}$, which is well below the potential at which faradic current can flow. The frequency of the signal was $100 \mathrm{kHz}$ to $1 \mathrm{mHz}$. The cell's response to the signal was a measured output amplitude and phase shift. This information enabled us to calculate the impedance of the cell. Where the real part of the impedance was independent of frequency, we called the value the cell's resistance. Knowing the cell's resistance and cell constant, we were able to establish the conductance of the electrolyte.

\section{Discussion of Experimental Results}

\subsection{The Equilibrium Potentials vs. Reference Electrode}

Because we are using a quasi-reference electrode, which by definition cannot give direct thermodynamic information, the following explains how we used thermodynamics and slow LSV $\left(1 \mathrm{mV} \mathrm{s}^{-1}\right)$ to connect our measured potentials vs. our reference electrode to a "well-defined" overvoltage. The overvoltage at a given working electrode is the applied potential minus an equilibrium potential. The connection necessitated defining an equilibrium potential for our cathode and anode vs. our quasi reference electrode.

We use the voltammograms shown in Fig. 3 to make the link for our electrochemical system at $1250 \mathrm{~K}$. These scans included a full cell linear sweep as well as linear sweeps of each working electrode with respect to the quasi reference electrode.

We begin with a discussion of the two cathode linear sweeps, $1^{\text {st }}$ and $2^{\text {nd }}$, as shown in Fig. 3. The first scan is in the cathodic direction, the second is reversed and in the 
anodic direction. During the forward cathodic scan, magnesium first forms on the electrode. During the reverse scan the current follows that of the cathodic scan until it crosses the -x-axis. Positive current indicates the oxidation of the Mg. Such a response is indicative

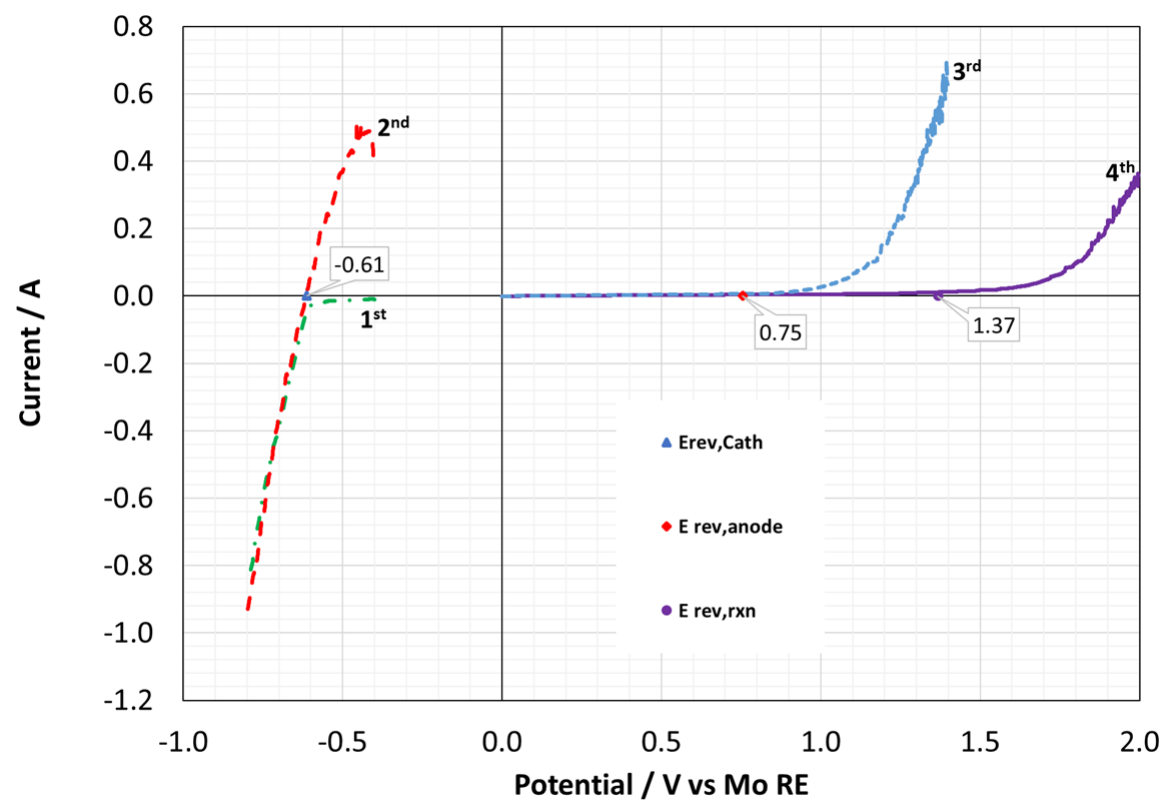

Fig. 3. Linear sweep voltammetry obtained at a three-electrode cell in the molten $\left(\mathrm{MgF}_{2}\right.$ - $\left.\mathrm{CaF}_{2}\right)_{\text {EUT }}$ - $\mathrm{MgO}$ (sat) system. $1^{\text {st }}$ - working electrode: Mo, auxiliary: graphite, reference: Mo, cathodic scan; $2^{\text {nd }}$ - working electrode: Mo, auxiliary: graphite, reference: Mo, anodic scan; $3^{\text {rd }}-$ working: graphite, auxiliary: Mo, reference: Mo; $4^{\text {th }}-$ cathode: Mo, anode: graphite, polarization of the whole cell.

of reversible kinetics. We call the potential at zero current the equilibrium potential of our cathode with respect to our Mo reference electrode at $1250 \mathrm{~K}$. The value is $(-0.61)$ V.

We calculate the reversible potential for our cell reaction from available thermodynamic data, assuming all species are in their standard states (NIST-JANAF Thermodynamical 
Tables, on line 9/25/2015). The overall cell reaction is given as eqn. 1 . The corresponding reversible cell voltage is $1.37 \mathrm{~V}$. Furthermore, this calculated potential agrees with the measured value of $1.37 \mathrm{~V}$ shown in the voltammogram in Fig. 3 for the linear sweep with the applied potential being that across the cell's anode and cathode. We thus define the reversible potential at the anode as the difference between the thermodynamic equilibrium potential of the cell and the measured equilibrium potential at the cathode.

Thus the anode potential is $0.75 \mathrm{~V}$ vs. our Mo reference electrode at $1250 \mathrm{~K}$. The LSV for the anode shown in the Fig. 3 corroborates the reasonableness of selecting this potential as the equilibrium potential for the anode: near this potential one observes the onset of current flow.

We acknowledge that this potential does not represent a standard reversible potential for the anode, but we argue that it does represent a reference potential for the anode that allows for communication of Tafel kinetics from a thermodynamically sound perspective. 


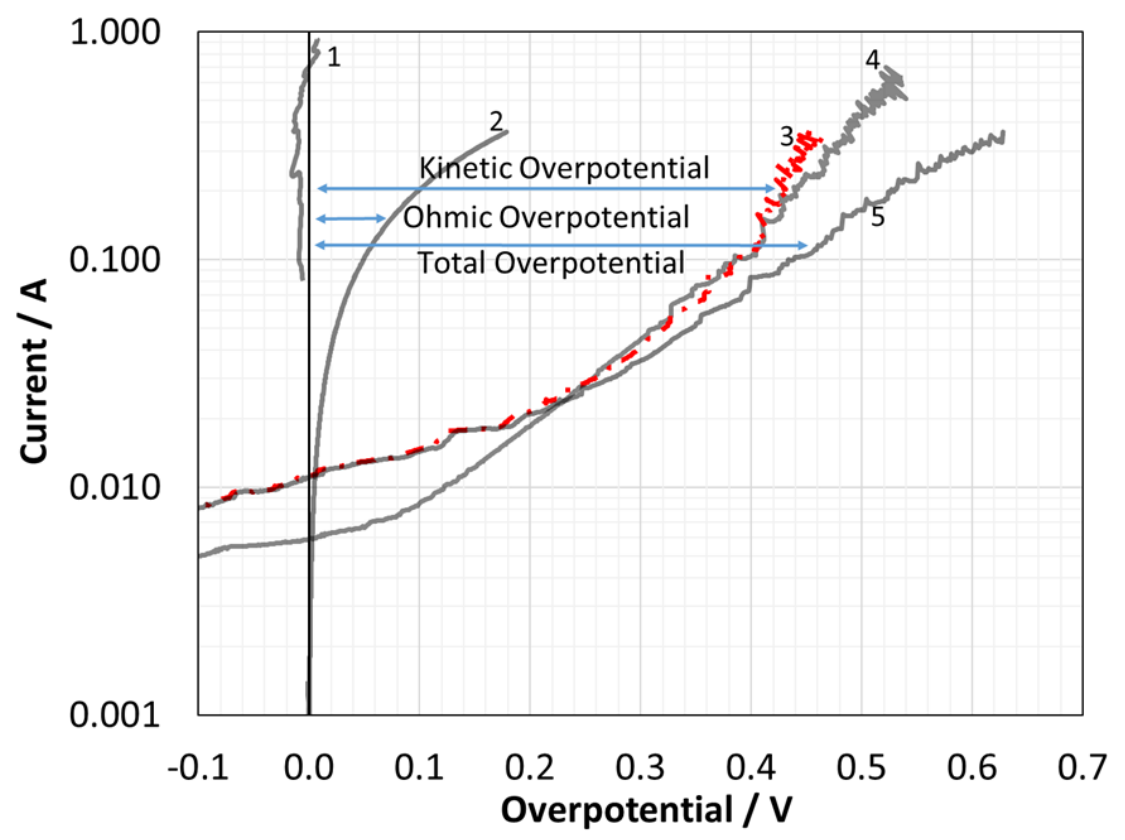

Fig. 4. Current as a function of overpotential obtained by slow linear sweep voltammetry at a three-electrode cell in the molten $\left(\mathrm{MgF}_{2}-\mathrm{CaF}_{2}\right)_{\text {EUT }}-\mathrm{MgO}$ (sat). 1 - IR corrected, working electrode: Mo, auxiliary: graphite, reference: Mo; 2 - IR uncorrected, working electrode: Mo, auxiliary: graphite, reference: Mo; 3 - IR corrected, cathode: Mo, anode: graphite; 4 - IR corrected, working electrode: graphite, auxiliary: Mo, reference: Mo; 5 IR uncorrected, cathode: Mo, anode: graphite.

\subsection{The Stability of the Quasi Reference Electrode}

We mentioned in the description of the experimental apparatus that it is critical that after IR correction, all applied potential change between the reference electrode and the working electrode occurs between the working electrode and the electrolyte. In a previous section, we gave evidence that this requirement was met, here we add to that evidence.

The data from Fig. 3, is presented again in Fig. 4, with the following changes: We plot the current vs. overvoltage for the cathode, anode and cell. Furthermore we show the current vs. cell overvoltage with and without IR correction. 
The full cell potential measurement with IR correction does not involve the reference electrode. The cathode kinetic overvoltage is close to zero and therefore does not contribute measurably to the cell overvoltage. Because the anode overvoltage is nearly identical to that for the cell, it is clear that there is not a measurable change in the interfacial potential due to the reference electrode. In summary, our Mo quasi reference electrode was suitable for our kinetic studies.

\subsection{The Global View of Overvoltage as Described in Equation (2)}

The results for the slow LSVs shown in Fig.4 indicate that the overvoltage at the anode dominates cell performance. For a first approximation of cell performance, it would be valid to ignore contributions from the cathode. As expected, the ohmic contribution to the overvoltage increases with current, but for the conditions of our cell it represents at most about one third of the total, where the current is $0.3 \mathrm{~A}$, with a corresponding anode current density of $0.7 \mathrm{~A} \mathrm{~cm}^{-2}$.

\subsection{Cathode Kinetics}

\subsubsection{Steady State small overvoltage analysis without IR correction}

Figure 5 shows three typical, slow LSVs for the cathode. The sweep rate was $1 \mathrm{mV} \mathrm{s}^{-1}$. At small overvoltage, for facile kinetics, the Bulter-Volmer equation can be approximated by the following equation (Bard and Faulkner, 2001):

$$
i=i_{0} \frac{n F}{R T} \eta,
$$


where $\eta$ does not include an IR voltage. Unfortunately, as can be observed from Fig. 6 , the ohmic contribution to the overpotential for our cell is at least an order of magnitude more significant than the cathodic overpotential. As a result, IR-corrected voltammograms were noisy.

We thus developed a method of analysis that incorporated total overpotential, $\eta_{t}(\mathrm{IR}+$ kinetics) into Equation 10 and applied it to our uncorrected voltammograms. Specifically, we substitute $\eta=\eta_{t}-i R_{e}$ into Equation 10 . Thus the current density becomes:

$$
i=\frac{i_{0} \frac{n F}{R T}}{1+i_{0} R_{e} \frac{n F}{R T}} \eta_{t}
$$

Equation (11) can be rearranged so that the desired exchange current density is expressed as a function of the electrolyte resistance and the slope $(m)$ of current density $(I)$ vs potential $\left(\eta_{t}\right)$ :

$$
i_{0}=\frac{m R T}{F} \frac{1}{1-m R_{e}}
$$

The slope of the linear fit leads to an estimated exchange current density. An average of three LSVs gives $14.9 \mathrm{~A} \mathrm{~cm}^{-2}$. 


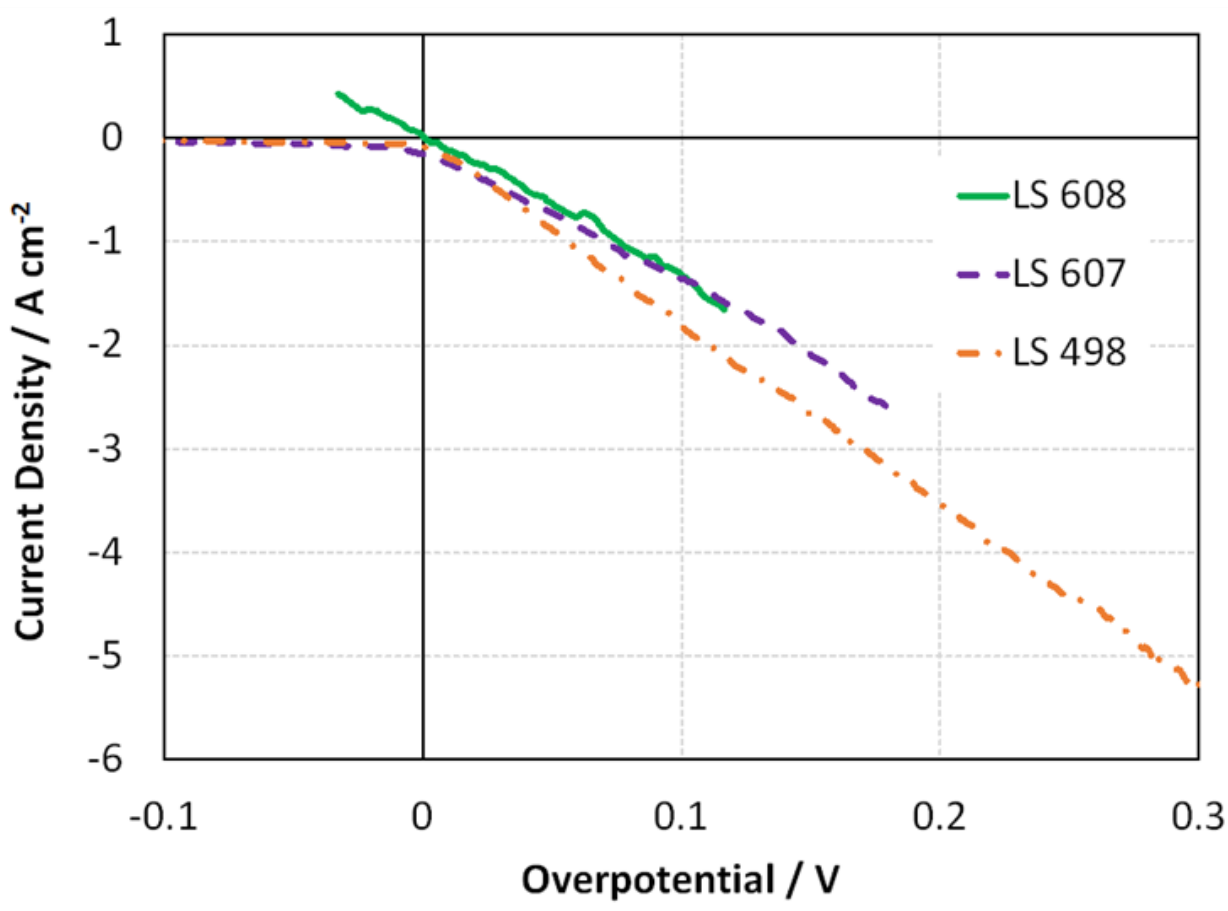

Fig. 5. Current as a function of overpotential obtained by slow linear sweep voltammetry $\left(1 \mathrm{mV} \mathrm{s}{ }^{-1}\right)$ obtained on two different days in molten $\left(\mathrm{MgF}_{2}-\mathrm{CaF}_{2}\right)_{\text {EUT }}$; working electrode: Mo, auxiliary: graphite, reference: Mo; LS 608 and 607 (with MgO) $-R_{e}=$ $0.2200 \Omega$, LS 498 (without $\mathrm{MgO}$ ) $-\mathrm{R}_{\mathrm{e}}=0.3081 \Omega$.

3.4.2 Transient Methods: Chronoamperometry: obtaining the exchange current density, the transfer coefficient, and the diffusion coefficient of the electroactive species 


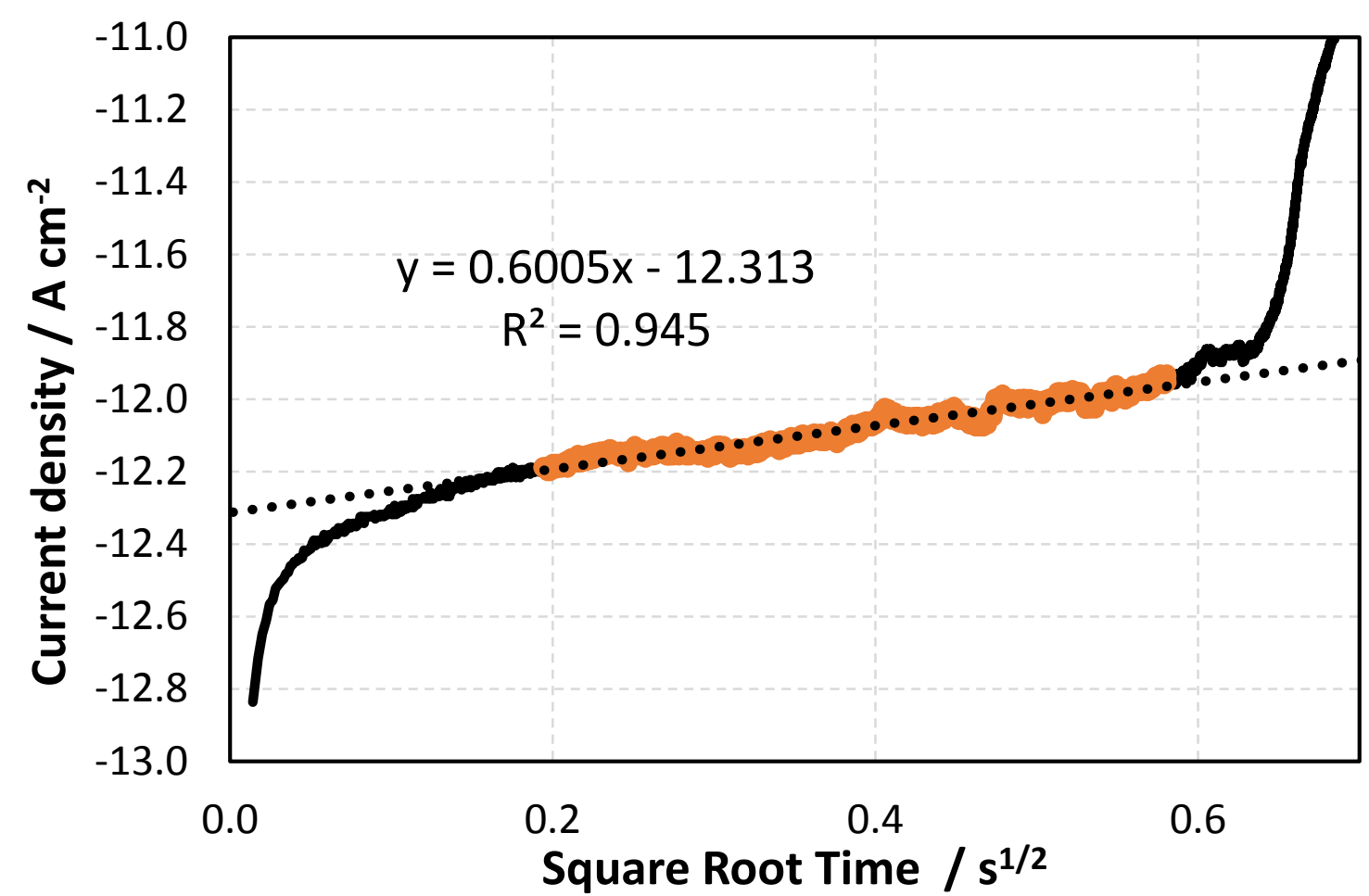

Fig. 6. A characteristic chronoamperogram in molten $\left(\mathrm{MgF}_{2}-\mathrm{CaF}_{2}\right)_{\mathrm{EUT}}-\mathrm{MgO}$ (sat); working electrode: Mo, auxiliary: graphite, reference: Mo.

Although LSV provides an estimate of exchange current density, it does not provide all the necessary parameters required for the Butler-Volmer equation. Specifically, the transfer coefficient, $\alpha$, is needed. To obtain the coefficient, we pushed the electrode overvoltage outside of this linear kinetics region with the chronoamperometry method. A typical chronoamperometric response is shown in Fig. 6. In the initial response, the interface is charged by high negative, capacitive current. After this initial capacitive current dissipates (in circa10 ms), the current is faradaic. Assuming the initial concentration of products on the surface is zero, the faradaic current response at short time scales can be expressed as (Bard and Faulkner, 2001): 


$$
i=F A k_{f} c_{O}^{B}\left(1-\frac{2 H t^{\frac{1}{2}}}{\pi^{\frac{1}{2}}}\right)
$$

where $H$ is a function of the rate constants and diffusion coefficients:

$$
H=\left(\frac{k_{f}}{D_{O}^{1 / 2}}+\frac{k_{r}}{D_{R}^{1 / 2}}\right)
$$

Equation (13) shows that the $y$-intercept on a plot of current vs. square root of time gives a kinetically limited current density:

$$
i_{k}=F A k_{f} C_{O}^{B}
$$

Using four potential-step experiments, we plotted the kinetically limited current as a function of overpotential. The result is shown in Fig. 7.

By extrapolating the current to zero time, the concentration of the products and reactants can be considered that of the bulk. Thus the anodic component of the current in Equation 7 is zero, and our Butler-Volmer equation reduces to the following form for the kinetically limited current:

$$
i_{k}=-i_{0} \exp \left\langle\frac{\alpha n F}{R T} \eta\right\rangle
$$

A regression of $\ln \left(i_{k}\right)$ vs. $\eta$ gives a slope of $\frac{\alpha n F}{R T}$ and an intercept of $\ln \left(i_{0}\right)$. We thus estimate the transfer coefficient and the exchange current density from chronoamperometry as 0.62 and $11.3 \mathrm{~A}-\mathrm{cm}^{-2}$ respectively. 


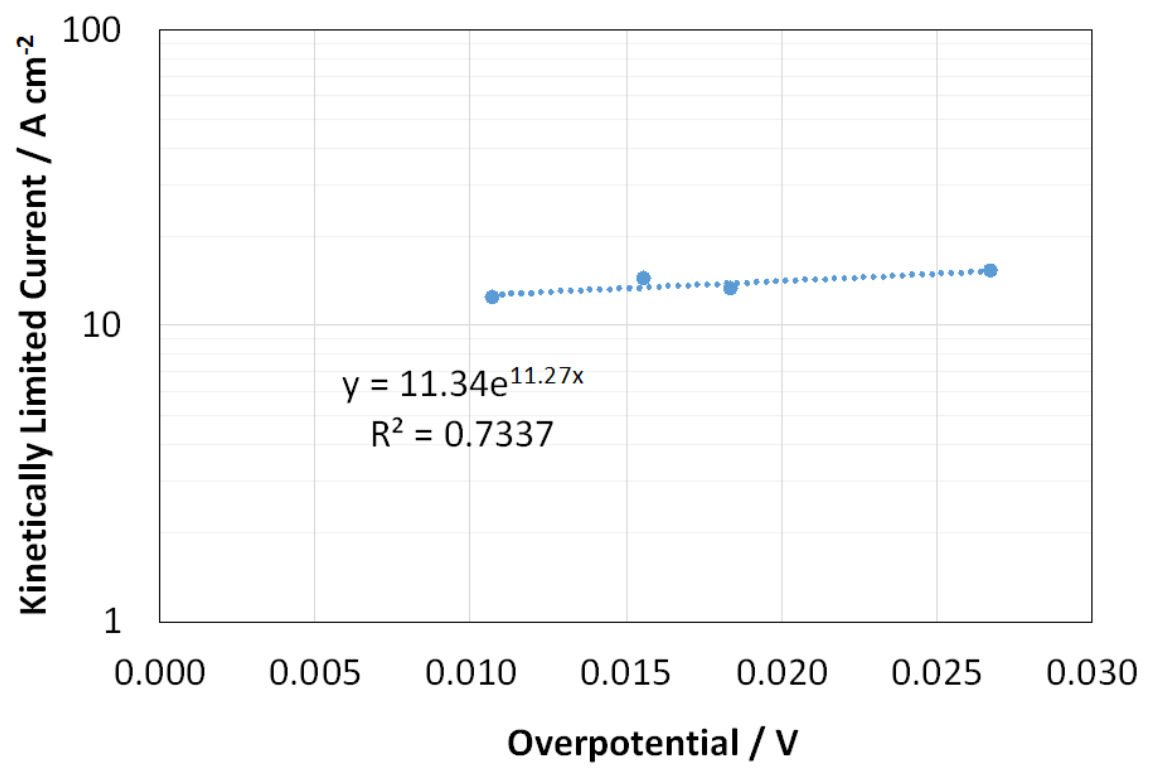

Fig. 7. Kinetically limited current density as a function of IR corrected overpotential. Electrolyte: $\left(\mathrm{MgF}_{2}-\mathrm{CaF}_{2}\right)_{\text {EUT }}$; working electrode: Mo, auxiliary: graphite, reference: Mo.

The results from our chronoamperometry experiments at times greater than $250 \mathrm{~ms}$ are shown in Fig. 8. The current decreases linearly with time to the $-1 / 2-0 r d e r$, a response indicative of a diffusion limited process describable by the Cottrell Equation (Bard and Faulkner, 2001):

$$
i=-\frac{n F A D_{R}^{1 / 2} C_{O}^{B}}{\pi^{1 / 2} t^{1 / 2}}
$$

We thus used the slope of the plot current vs. $t^{-1 / 2}$ to establish the diffusion coefficient as $5.3 \mathrm{E}-5 \mathrm{~cm}^{2} \mathrm{~s}^{-1}$ from an average of four measurements. 


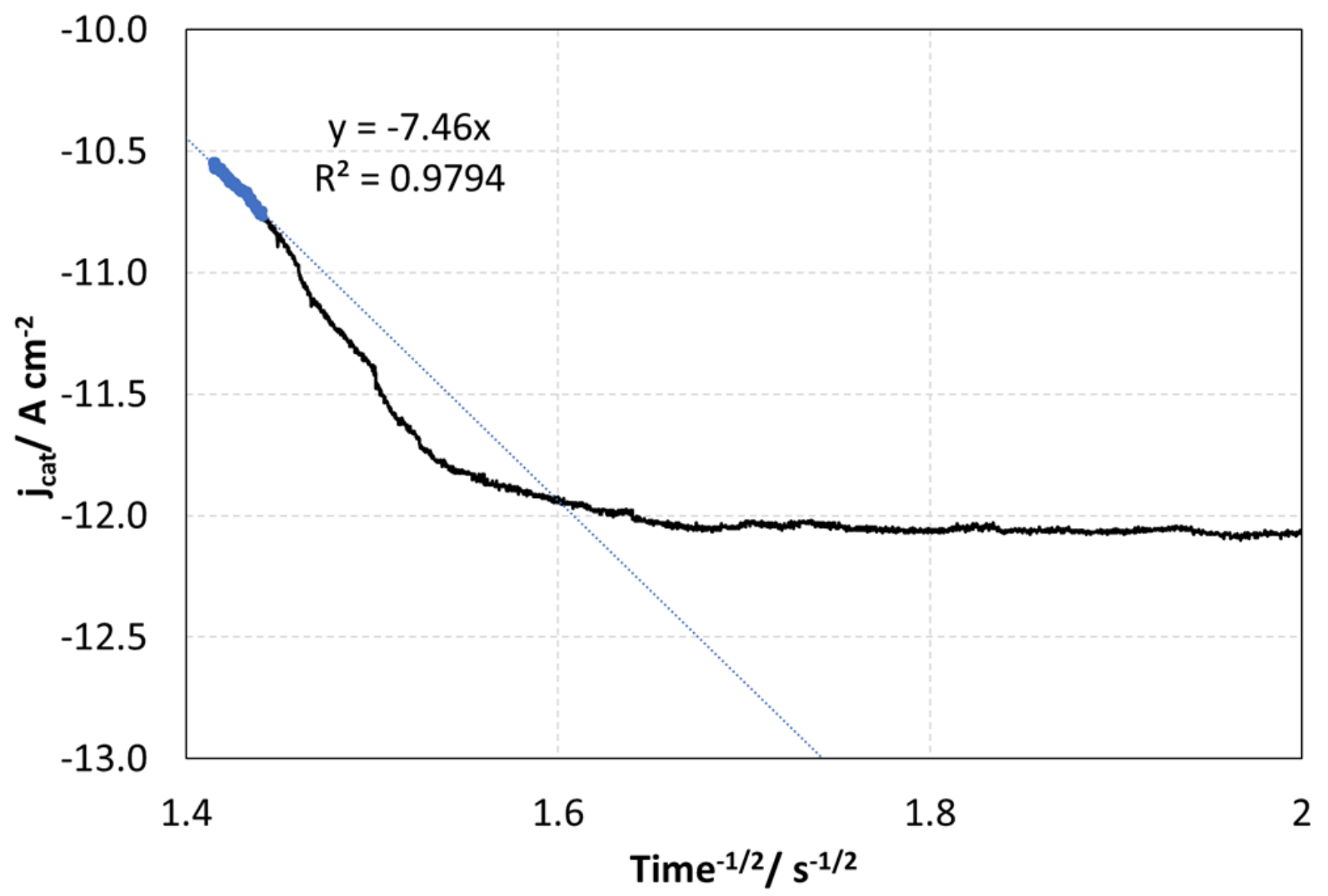

Fig. 8. Current density as function of inverse square root of time. Fitted region is diffusion limited. Electrolyte: $\left(\mathrm{MgF}_{2}-\mathrm{CaF}_{2}\right)_{\mathrm{EUT}}-\mathrm{MgO}$ (sat); working electrode: Mo, auxiliary: graphite, reference: Mo.

3.4.3 Transient Methods: Chronopotentiometry: a $2^{\text {nd }}$ approach for obtaining the

\section{diffusion coefficient}

We applied a step change in current to our cell and measured the transient voltage response between the cathode and reference electrode. From this response, we were able to detect the time at which the voltage rapidly transitioned to higher values in order to maintain the applied cell current. This transition time is called $\tau$. Knowing this time, the diffusion coefficient for $\mathrm{Mg}^{2+}$ is given by the Sand Equation (Bard and Faulkner, 2001): 


$$
\frac{n F D_{M g^{2+}}^{1 / 2} \pi^{1 / 2} C_{o}^{B}}{2}=j \tau^{1 / 2}
$$

Fig. 9 is a typical result.

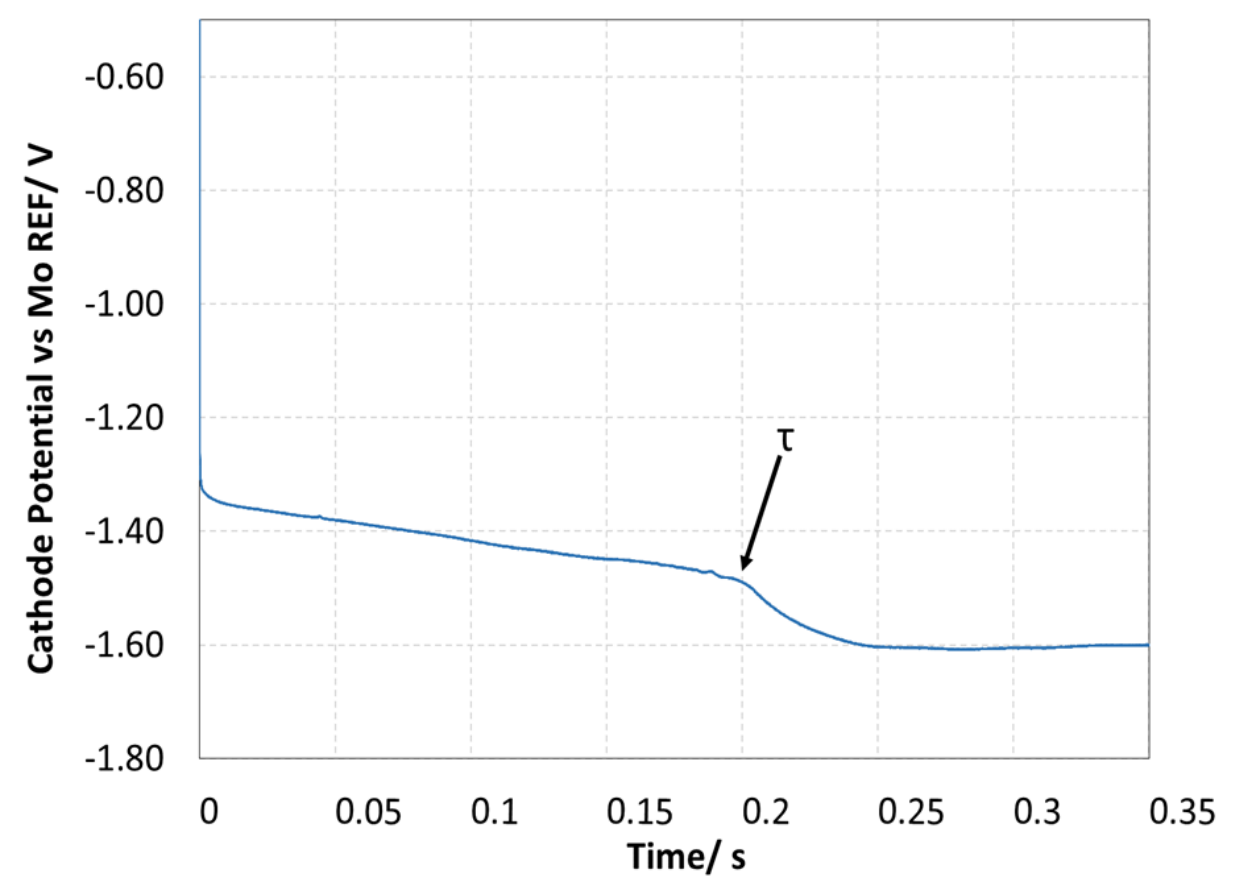

Fig. 9. Typical chronopotentiogram observed on molybdenum in molten $\left(\mathrm{MgF}_{2}-\right.$ $\left.\mathrm{CaF}_{2}\right)_{\text {EUT; }}$; auxiliary electrode: graphite, reference: Mo.

Using Equation (18), we established the diffusion coefficient from several chronopotentiometry runs. The applied step potentials were from 2.85 to $2.55 \mathrm{~V}$ in 0.05 $V$ increments. The average value at $T=1250 \mathrm{~K}$ was $5.2 \mathrm{E}-5$ with a variability of \pm 0.3 $\mathrm{E}-5 \mathrm{~cm}^{2}-\mathrm{s}^{-1}$

The values are reasonable: they are consistent with the values we obtained by chronoamperometry, and they are similar to values reported in the literature for an electrolyte of molten $\mathrm{MgCl}_{2}$ at $1000 \mathrm{~K}, 5.0 \mathrm{E}-5 \mathrm{~cm}^{2} \mathrm{~s}^{-1}$ (Kisza et al., 1993). 
We have characterized the kinetics and mass transport processes for the cathode. Unequivocally, we can state that the electrochemical reaction is fast, and the overvoltage at the cathode is not contributing significantly to the total overvoltage of the cell at any practical current density.

Table 1. The electrochemical kinetics and mass transport parameters for the cathode.

\begin{tabular}{|c|c|c|c|}
\hline Method & $i_{0} \mathrm{~A} \mathrm{~cm}^{-2}$ & $\alpha$ & $D_{\mathrm{Mg}^{2+} \mathrm{cm}^{2} \mathrm{~s}^{-1}}$ \\
\hline $\begin{array}{c}\text { Linear Sweep } \\
\text { Voltammetry }\end{array}$ & 15 & $\mathrm{NA}$ & $\mathrm{NA}$ \\
\hline Chronoamperometry & 11 & 0.62 & $5.3 \mathrm{E}-5$ \\
\hline Chronopotentiometry & $\mathrm{NA}$ & $\mathrm{NA}$ & $5.2 \mathrm{E}-5$ \\
\hline Best Estimate Value & $11 \pm 4$ & $0.50 \pm 0.12$ & $5.3 \pm 0.6 \mathrm{E}-5$ \\
\hline
\end{tabular}

Our best estimate for the exchange current density comes from the chronoamperometry method. The value is the intercept of a regression analysis that is based on four points, each of which is the intercept of another regression based on more than 100 data points. We consider the value emerging from the linear sweep method as a concomitant check on our best estimate. Furthermore, we set the uncertainty interval such that our best estimate brackets this value.

We expect a transfer coefficient of 0.5 . We thus report it as our best estimate and prescribe an uncertainty interval large enough to bracket our measured value of 0.62 .

The best estimate of the diffusion coefficient is based on the standard error of $y$ estimate from the chronoamperometry regression analysis. It is our best estimate for the 
value due to the large number of data points considered in the regression analysis leading to the value. The confidence level on the regression analysis uncertainty interval is $95 \%$. The chronopotentiometry measurement serves as a concomitant check on this result.

More rigorous statements on the uncertainty intervals for each of these parameters will require contributions to this study by others in the electrochemistry community. We need to see how the results scatter between other laboratories using different as well as similar methods and equipment. But we have some corroborating evidence from the literature. Remarkably, our $i_{o}$ value is the value predicted from an EIS electrochemical technique used by Kisza et al. (1993) when we extrapolate their $1000 \mathrm{~K}$ exchange current density in molten $\mathrm{MgCl}_{2}$ to $1250 \mathrm{~K}$ with their Arrhenius equation.

We will offer further insight on the validity of the parameters in the Finite Element Modeling Section of this article.

\subsection{The Anode Kinetics}

\subsubsection{Cyclic Voltammetry: overall picture of potential anode electrode reactions}

Very fast $(100-1000 \mathrm{~V} / \mathrm{s})$ cyclic voltammetry measurements were performed on the graphite anode in the molten system $\left(\mathrm{CaF}_{2}-\mathrm{MgF}_{2}\right)_{\mathrm{EUT}}-\mathrm{MgO}$ (sat) for the potential range $0-8 \mathrm{~V}$ vs. the molybdenum quasi reference electrode. All together five current peaks were observed (Fig.10).

The first peak (A1) occurs at $1.4-1.55 \mathrm{~V}$. (A2) is between potentials $2.02-2.12 \mathrm{~V}$. The third peak (A3) appears as a shoulder to the right of (A2), and a fourth peak (A4) 
only appears at the slowest scan rate. After a significant gap above the (A4) potential, a fifth peak (A5) occurs near $5 \mathrm{~V}$.

We think it is informative to note that similar CV results were reported by several authors (Jarek and Thonstad, 1987a; Jarek and Thonstad, 1987b; Thonstad et al., 2001; Zhu and Thonstad 2003) for a graphite electrode in the molten cryolite aluminasystem, the system used in the Hall-Héroult process for aluminum production. There are many similarities between the systems: the reactant for both systems is a metal oxide; the electrolyte of both systems is a fluoride salt, both systems operate near 1300 $\mathrm{K}$, and the anode is graphite. Based on this correspondence with the Hall-Héroult process, we hypothesize that the electroactive species in our system is also an oxyfluoro complex anion due to the solvation of the metal oxide in the molten fluoride electrolyte (Thonstad et al., 2001).

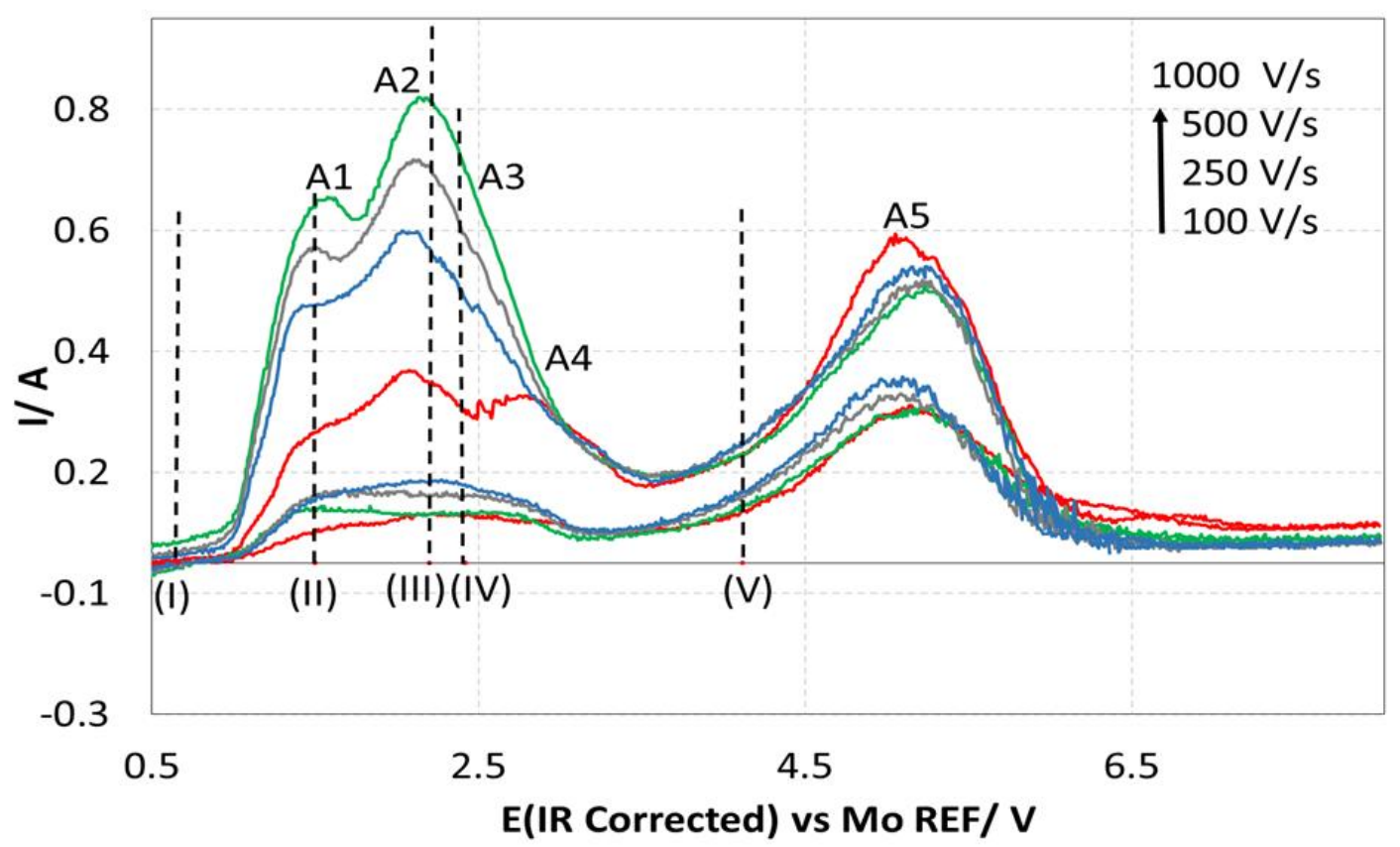


Fig. 10. Cyclic voltammograms obtained at a graphite electrode in the molten $\left(\mathrm{MgF}_{2}-\right.$ $\left.\mathrm{CaF}_{2}\right)_{\mathrm{EUT}}-\mathrm{MgO}$ (sat); auxiliary electrode: Mo, reference: Mo; dashed lines represent potentials of half-reactions I-V listed in the text.

For each of the peaks above, we propose an electrochemical half-cell reaction. We follow closely the reactions proposed for similar voltammograms for the cryolite-alumina system (Jarek and Thonstad, 1987a; Thonstad et al., 2001). The Roman numerals correspond to the $A 1, A 2$, etc. peaks in the above voltammograms:

$\mathrm{I}(\mathrm{A} 1)$

$$
\mathrm{Mg}_{2} \mathrm{OF}_{4(\text { diss })}^{2-}+\frac{1}{2} \mathrm{C} \leftrightarrow \frac{1}{2} \mathrm{CO}_{2(g)}+2 \mathrm{MgF}_{2(\text { diss })}+2 e^{-}
$$

II(A2)

$$
\frac{1}{2} \mathrm{Mg}_{2} \mathrm{OF}_{4(\text { diss })}^{2-}+\frac{1}{2} \mathrm{CO}_{(\text {ads })}
$$

$$
\leftrightarrow \frac{1}{2} \operatorname{COF}_{2(g)}+M g F_{2(d i s s)}+\frac{1}{2} M g^{2+}+2 e^{-}
$$

III(A3)

$$
M g F_{2(d i s s)}+C \leftrightarrow C F_{4(g)}+M g^{2+}+2 e^{-}
$$

IV(A4)

$$
\frac{3}{2} M g F_{2(d i s s)}+C \leftrightarrow \frac{1}{2} C_{2} F_{6(g)}+\frac{3}{2} M g^{2+}+e^{-}
$$

$\mathrm{V}(\mathrm{A} 5)$

$$
M g F_{2} \leftrightarrow F_{2(g)}+M g^{2+}+2 e^{-}
$$

The measured potentials for all peaks are higher than the calculated thermodynamic potentials by values less than a volt. The difference is not surprising because the electrochemical reaction is expected to be irreversible and the measured peaks should all be at potentials higher than reversible values. Furthermore the relative position of measured peaks with respect to each other is consistent with thermodynamic values. It is thus reasonable to assume $\mathrm{A} 1$ is due to $\mathrm{CO}_{2}$ evolution. The peak $\mathrm{A} 2$ is due to the 
formation of $\mathrm{COF}_{2}$ and shoulders $\mathrm{A} 3$ and $\mathrm{A} 4$ to the formation of perfluorocarbon species $\mathrm{CF}_{4}$ and $\mathrm{C}_{2} \mathrm{~F}_{6}$, respectively. We suggest that the most positive peak $A 5$ represents fluorine evolution.

During bulk electrolysis we obtained some support for our peak correlations: we detect $\mathrm{CO}_{2}$ evolution at the anode with a micro-GC, a product that is consistent with what we hypothesize for peak A1. Further evidence supporting our peak correlation to half-cell reactions is given in the next section, namely a diffusion analysis of $\mathrm{A} 2$ and $\mathrm{A} 3$ should yield similar diffusion coefficients for the $\mathrm{Mg}_{2} \mathrm{OF}_{4}{ }^{2-}$ species.

\subsubsection{Cyclic Voltammetry: diffusion coefficient for $\mathrm{Mg}_{2} \mathrm{OF}_{4}^{2-}$}

The peak currents of peaks $A 2$ and $A 3$ are linearly dependent on the square root of the scan rate, $v^{1 / 2}$. The graphs are shown in Fig. 11. Although we cannot conclusively identify the peaks as asymmetric, a form indicative of diffusion control, the linear dependence of peak current with the half-order scan rate suggests diffusion control. Furthermore, for additional validation of diffusion control these CV values will be compared to independently calculated diffusion coefficient values from data obtained with alternative electrochemical methods. We thus calculated the diffusion coefficient for the $\mathrm{Mg}_{2} \mathrm{OF}_{4}{ }^{2-}$ anion from the following equation (Bard and Faulkner, 2001):

$i_{p}=0.4958 \frac{F^{3 / 2}}{(R T)^{1 / 2}} \alpha^{1 / 2} A c_{R}^{B} D_{R}^{1 / 2} v^{1 / 2}$

Assuming a transfer coefficient value of 0.5 , we estimate $D\left(\mathrm{Mg}_{2} \mathrm{OF}_{4}{ }^{2-}\right)$ to be $0.7 \mathrm{E}-5 \mathrm{~cm}^{2}$ $\mathrm{s}^{-1}$ from an analysis of $A 1$ peaks (solid circles) and $1.4 \mathrm{E}-5 \mathrm{~cm}^{2} \mathrm{~s}^{-1}$ from an analysis of A2 peaks (open circles). As expected, the values are similar. We argue that the value 
from an analysis of the $\mathrm{A} 2$ peaks is higher than that from the A1 peaks because the current at A2 includes a contribution from reaction III.

It should be noted that Equation (19) assumes a constant scan rate. The large IR drop due to high currents does change the actual scan rate that the electrode-electrolyte interface feels. We calculated effective scan rates. They were lower by about $15 \%$ (at $100 \mathrm{~V} \mathrm{~s}^{-1}$ ) to $25 \%$ (at $1000 \mathrm{~V} \mathrm{~s}^{-1}$ ) than the imposed scan rates. This likely accounts for some of the negative curvature seen in the data in Fig. 13. We thus consider these estimates to be concomitant evidence to support what we offer as the diffusion coefficient determined from other methods.

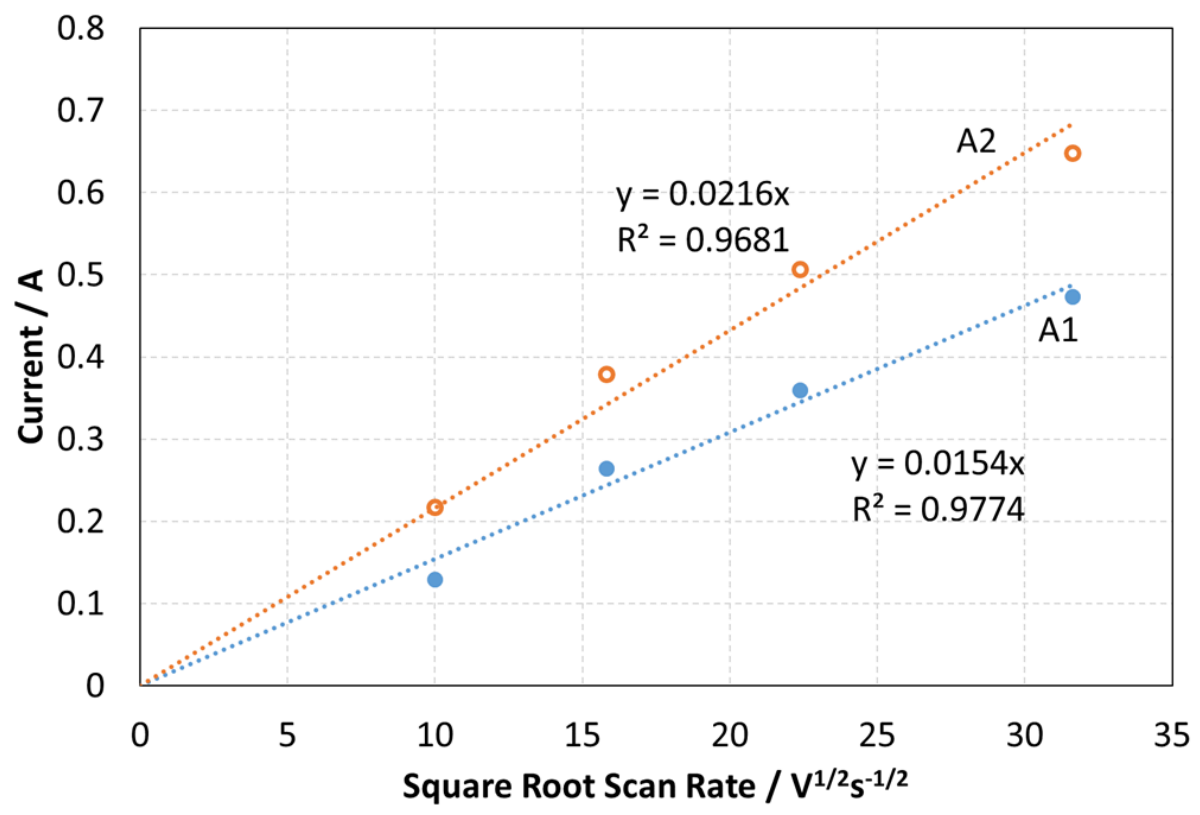

Fig. 11. Peak current ( $\mathrm{A} 1$ and $\mathrm{A} 2)$ as a function of square root scan rate; $\left(\mathrm{MgF}_{2}-\right.$ $\left.\mathrm{CaF}_{2}\right)_{\mathrm{EUT}}-\mathrm{MgO}$ (sat); working electrode: graphite, auxiliary: Mo, reference: Mo.

\subsubsection{Slow Linear Sweep Voltammetry: anode Tafel kinetics}


In Fig. 3, the third curve, one finds a typical LSV result. The scan rate was $1 \mathrm{mV} \mathrm{s}^{-1}$. We assumed that the surface concentration of the electroactive species is not changing significantly with potential. The data was fit to the Tafel equation described above as Equation (9). The overpotential was based on our equilibrium potential vs. the Mo electrode, $0.75 \mathrm{~V}$.

The Tafel fit to this data has a linear $r^{2}$ correlation of 0.997 . The Tafel slope is $0.215 \mathrm{~V}$ per decade. The exchange current density is $0.92 \mathrm{~mA} \mathrm{~cm}^{-2}$ for the data in Fig. 14. Data from a second LSV study conducted on a different day gave an exchange current density of $0.71 \mathrm{~mA} \mathrm{~cm}^{-2}$. It is important to note that this Tafel kinetics' result is valid for an overvoltage below $0.5 \mathrm{~V}$. In the last section of this article we suggest a second Tafel equation for describing kinetics for an overvoltage above $0.5 \mathrm{~V}$.

These kinetic results are consistent with those for the anode in the Hall-Héroult process. Although there is some variation in reported values for the Tafel slope, they range from 0.2 to $0.3 \mathrm{~V}$ per decade (Thonstad et al., 2001).

\subsubsection{Chronoamperometry: a transient analysis approach for anode Tafel kinetics}

Besides sweep voltammetry, the anode kinetics were also probed by chronoamperometry as with the cathode. A representative chronoamperometric response is shown in Fig. 12. Initially the electrode potential holds near the open circuit $(0.5 \mathrm{~V})$. Then a step change to the potential of interest is achieved. Finally, the electrode is stepped back to the original potential. This reverse step is used as a diagnostic to identify when the capacitive charging current has dissipated. The faradaic analysis begins in this region of minimal to no capacitive current. 
Fig. 12 shows three regions of a chronoamperometric step response. Initially we see a logarithmic decay, the signature for the charging of the interfacial capacitance. Then, after about $t^{1 / 2}=0.25 \mathrm{~s}^{1 / 2}$, a linear region develops. This $1 / 2$ order linear region indicates kinetic control and is analyzed using Equation (13). As with the cathode analysis, the yintercept indicates a kinetically controlled current. From the y-intercept of multiple potential-step experiments, a plot of kinetically controlled current vs. overpotential is developed as shown in Fig. 13. A Tafel fit allows for the calculation of exchange current density and of alpha from a plot of $\ln \left(i_{k}\right)$ vs. $\eta$ (see Equation 9). The fit (shown in Fig. 13) indicates an exchange current density of $0.77 \mathrm{~mA} \mathrm{~cm}^{-2}$ and an alpha of 0.54 for an overvoltage below $0.5 \mathrm{~V}$.

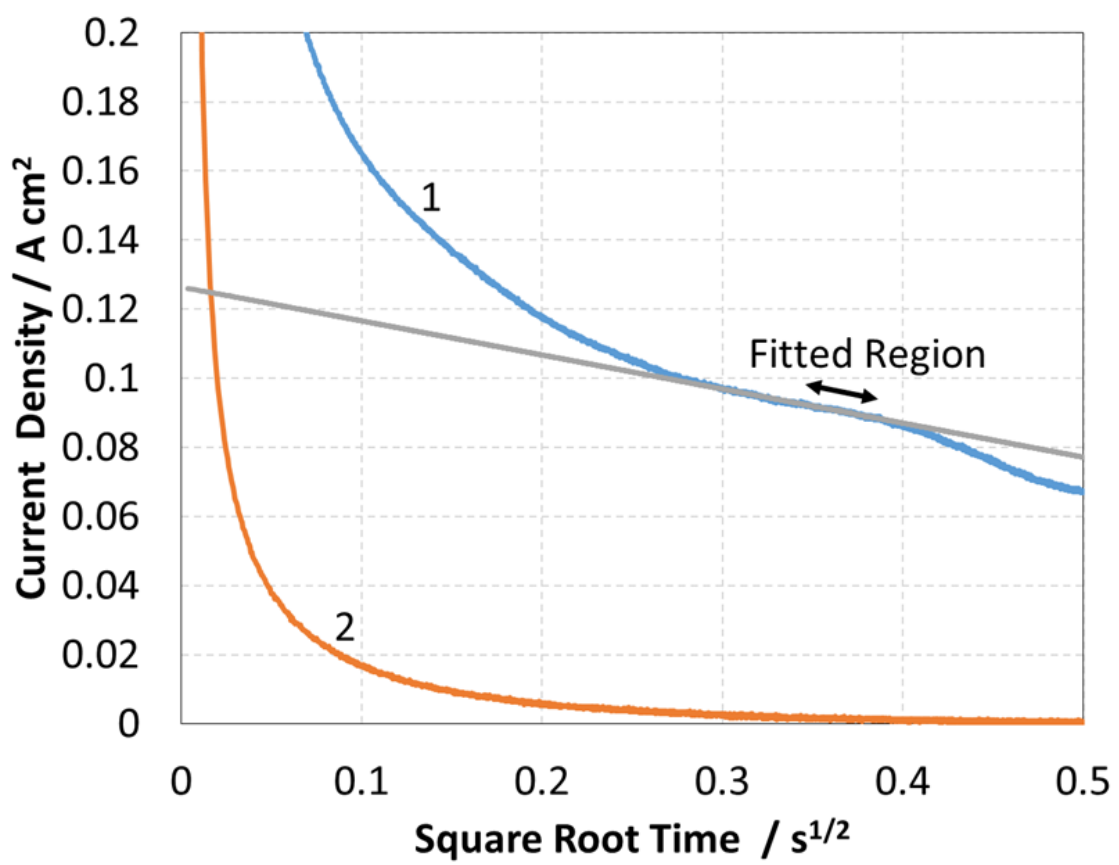

Fig. 12. Characteristic chronoamperogram observed in molten $\left(\mathrm{MgF}_{2}-\mathrm{CaF}_{2}\right)_{\mathrm{EUT}}-$ $\mathrm{MgO}$ (sat); working electrode: graphite, auxiliary: Mo, reference: Mo. 1 - step response, 2 - capacitive response. 
Chronoamperometric data that showed diffusion limiting regions were analyzed using the Cottrell Equation (Equation 17) as was done with the cathode. A characteristic Cottrell plot is shown in Fig. 14, and the quality of the zero-intercept fit is confirmation of diffusion limitations. We calculate a diffusion coefficient of $7.2 \mathrm{E}-6 \mathrm{~cm}^{2} \mathrm{~s}^{-1}$, a value consistent with our cyclic voltammetry result.

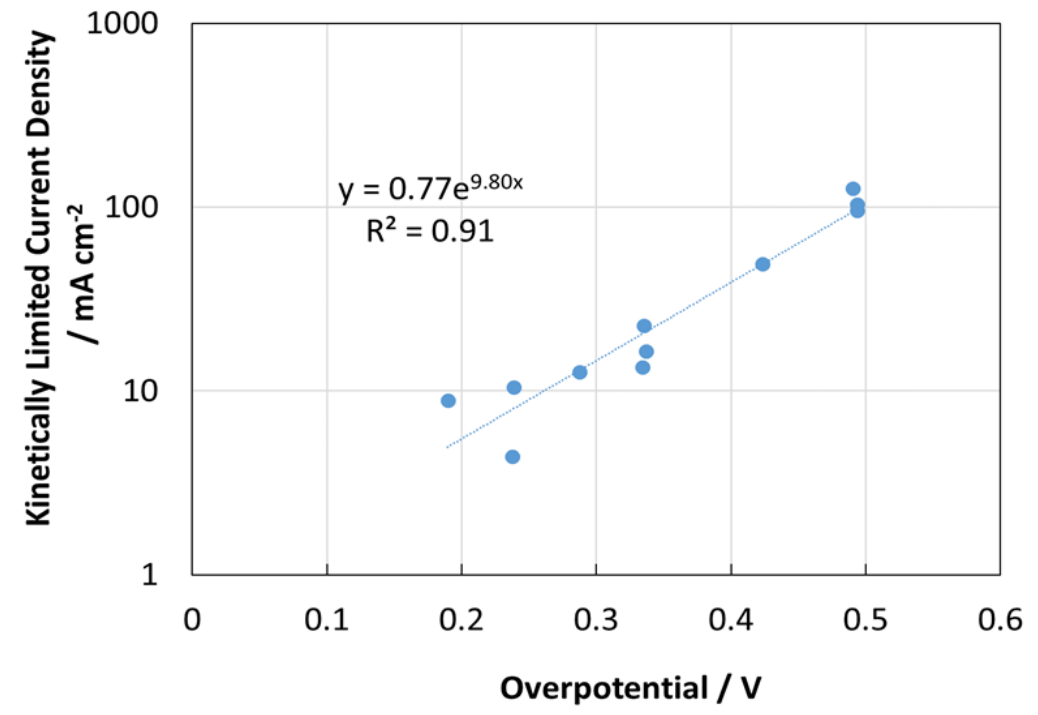

Fig. 13. Kinetically limited current density as a function of IR corrected overpotential. Electrolyte: $\left(\mathrm{MgF}_{2}-\mathrm{CaF}_{2}\right)_{\mathrm{EUT}}-\mathrm{MgO}$ (sat); working electrode: graphite, auxiliary: Mo, reference: Mo.

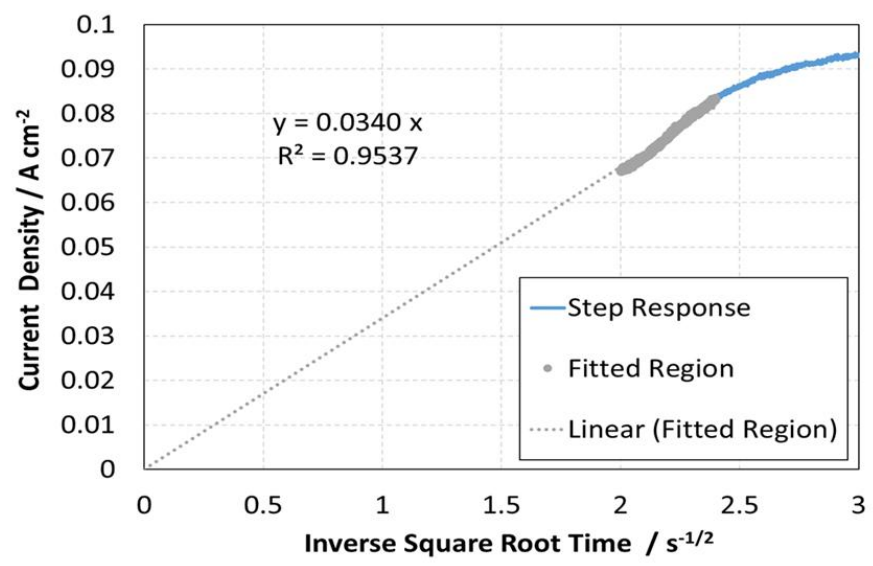

Fig. 14. Current density as function of inverse square root of time. Fitted region is diffusion limited. Electrolyte: $\left(\mathrm{MgF}_{2}-\mathrm{CaF}_{2}\right)_{\mathrm{EUT}}-\mathrm{MgO}$ (sat); working electrode: graphite, auxiliary: Mo, reference: Mo. 


\subsubsection{Electrochemical Impedance Spectroscopy: a $2^{\text {nd }}$ Steady State Analysis}

\section{Approach for Anode Tafel Kinetics}

\subsubsection{The Equivalent circuit}

Besides chronoamperometry, the other technique used to analyze the anode system was electrochemical impedance spectroscopy. The spectra were fit to the following equivalent circuit (Kisza et al., 1999):

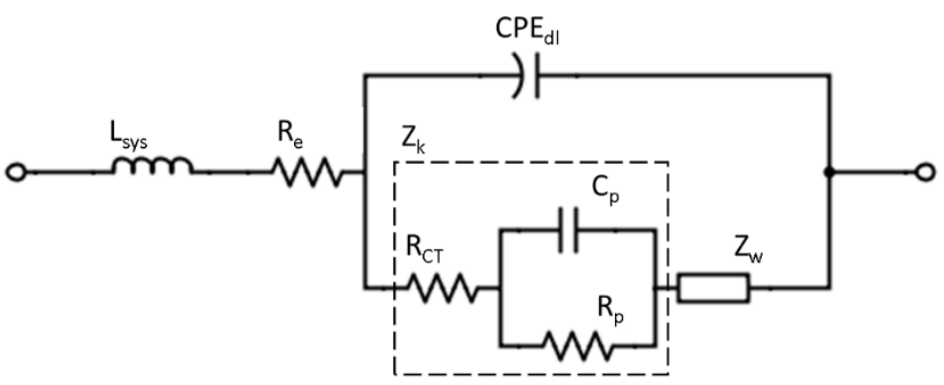

Fig. 15. Equivalent electrical circuit used in the electrochemical impedance spectroscopy analysis. The circuit elements were chosen based on the perceived underlying physics of the electrode processes.

Where $L_{\text {sys }}$ represents the inductance of the system, $R_{e}$ represents the electrolyte resistance, $\mathrm{CPE}_{\mathrm{dl}}$ is a constant phase angle element representing the non-ideal capacitance of the double layer, $R_{C T}$ represents the charge transfer resistance, $C_{p}$ and $R_{p}$ model the impact of an adsorbed intermediate on the electrode, and $Z_{w}$ represents the Warburg impedance associated with diffusion of reactants to the surface. Most of these elements will require further justification. 
For example, the constant phase angle element modeling the double layer capacitance needs explanation. The interfacial capacitance is a phenomenon that we have been dealing with throughout this work for all the techniques, but for EIS we cannot simply neglect its effect and concentrate on faradaic current. Further complicating this situation is the fact that the electrode interface does not act like a typical electrical capacitor. The porosity of the graphite anode causes the capacitance to be spread out through a finite depth of the electrode. As a result, the interface acts as a combination of resistance and capacitance. This idea results in behavior we are attempting to capture with a constant phase element. Evidence of this constant phase element will be found later in this section from the EIS spectra (Barsoukov and MacDonald, 2005).

Another element of the equivalent circuit that requires further explanation is the $R_{C T}$. It can be written as the charge transfer resistances of the two electrochemical steps in parallel (Orazem and Tribollet, 2008):

$$
R_{C T}^{-1}=R_{C T, 1}^{-1}+R_{C T, 2}^{-1}
$$

The overall charge transfer impedance can be written as (Harrington and Conway, 2008; Orazem and Tribollet, 2008):

$$
Z_{k}=R_{C T}+\frac{1}{R_{p}^{-1}+C_{p} j \omega}
$$


In this equation, the charge transfer resistance corresponds to the charge transfer resistance in the equivalent circuit, and the remainder of the right hand side is modeled as a capacitor $\left(C_{p}\right)$ and resistor $\left(R_{p}\right)$ in parallel also shown in the circuit.

In the anode system we expect bubbling associated with the formation of $\mathrm{CO}_{2}$ to induce convection near the surface. For the purposes of impedance we assume that this convection creates a fixed boundary layer and thus can be modeled by the bounded diffusion version of the Warburg impedance (Lvovich, 2012):

$$
Z_{w}=\frac{R T}{n^{2} F^{2} c \sqrt{D j \omega}} \tanh \left(\delta \sqrt{\frac{j \omega}{D}}\right)
$$

The justification for this diffusion impedance will be discussed below with reference to the shape of the impedance spectra.

In the fitting of the above equivalent circuit, the system inductance was calculated from a regression of high frequency data. At high frequency, the constant phase element behaves as a short circuit. As a result, at high frequency, the entire impedance of the electrochemical interface is shorted by the double layer capacitance and the total impedance reduces to the electrolyte resistance in series with the system inductance:

$$
Z=R e+j \omega L s y s
$$




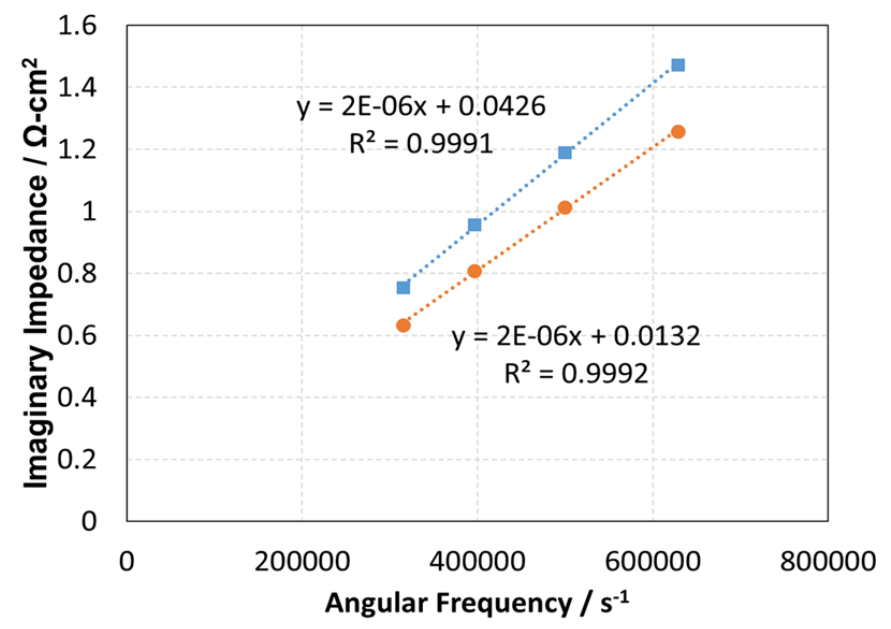

Fig. 16. Imaginary impedance as a function of angular frequency; $\left(\mathrm{MgF}_{2}-\mathrm{CaF}_{2}\right)_{\mathrm{EUT}}-$ $\mathrm{MgO}$ (sat); working electrode: graphite, auxiliary: Mo, reference: Mo. The slope of the linear regression line is the system's inductanace.

With this behavior, the imaginary impedance is linear with respect to frequency (Fig. 16), and the slope of the regression gives the system inductance. Spectra were corrected for inductance via this method and fit to the impedance of the remainder of the equivalent circuit with our MATLAB code:

$$
Z=R e+\left[Y(j \omega)^{a}+\frac{1}{Z_{C T}+Z_{W}}\right]^{-1}
$$

\subsubsection{Fit of the Equivalent circuit}

Fig. 17 is representative of a kinetically limited spectrum showing two charge transfer loops. The points represent the data and the dashed line is the corresponding fit from our model. The diameter of the first loop represents the total charge transfer resistance of the interface (Equation 20). It is evident that this charge transfer resistance is not the 
expected perfect semicircle. Instead, the charge transfer loop is somewhat flattened. This decrease in aspect ratio of the charge transfer loop is likely the result of the porosity of the electrode. As discussed earlier, the porosity of the electrode causes the interface to have a finite active thickness (Barsoukov and MacDonald, 2005).

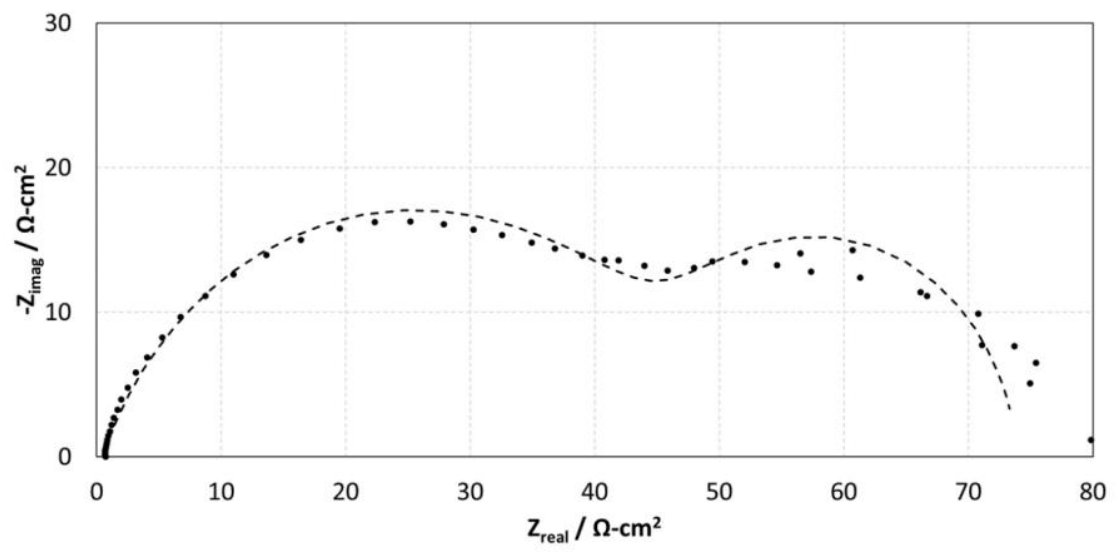

Fig. 17. Characteristic Nyquist plots of impedance spectrum at a low overpotential $(0.09 \mathrm{~V})$ observed in molten $\left(\mathrm{MgF}_{2}-\mathrm{CaF}_{2}\right)_{\mathrm{EUT}}-\mathrm{MgO}$ (sat); working electrode: graphite, auxiliary: Mo, reference: Mo.

The second charge transfer loop represents the impact of the intermediate surface species on the impedance, a result consistent with the findings of those who studied the anode for the Hall-Héroult process. These intermediate charge transfer loops can be capacitive (as in Fig. 20) indicating high surface coverage, or inductive indicating low surface coverage (Orazem and Tribollet, 2008). For the present system, the large capacitive intermediate charge transfer loop shown in Fig. 17 suggests nearly complete coverage by a surface species. Because we have detected $\mathrm{CO}$ as a product from bulk electrolysis, we argue that it is likely that this intermediate is CO. It is known to be a strong adsorbent and is also hypothesized to be an intermediate in $\mathrm{CO}_{2}$ generation for the Hall-Héroult process (Thonstad et al., 2001). 
In order to deal with the kinetics more quantitatively, a charge transfer resistance for Tafel kinetics can be expressed as (Orazem and Tribollet, 2008):

$$
R_{C T}=\frac{1}{i_{0} \frac{\alpha n F}{R T} \exp \left(\frac{\beta n F}{R T} \eta\right)}
$$

This charge transfer expression was used to calculate a Tafel relationship for the kinetics by a linear regression of the parameter $\ln \left(1 / R_{C T}\right)$ vs. overpotential:

$$
\ln \left(\frac{1}{R_{C T}}\right)=\frac{\alpha n F}{R T} \ln \left(i_{o}\right)+\frac{\beta n F}{R T} \eta
$$

An exchange current density and transfer coefficient can be calculated from the slope and intercept. With the transfer coefficient established, kinetically limited currents are calculated from charge transfer resistances for direct comparison with chronoamperometry:

$$
i_{k}=\frac{R T}{\beta n F R_{C T}}
$$

The kinetically limited current values are shown in Fig. 18 for both this EIS analysis and from linear sweep voltammetry. These current values were fitted to the Tafel expression shown in Equation (9). The exchange current density $\left(i_{0}\right)$ was $1.1 \mathrm{~mA} \mathrm{~cm}^{-2}$, and the transfer coefficient $(\alpha)$ was circa 0.5 . It should be noted that these values only include spectra with overvoltage of less than $0.4 \mathrm{~V}$. At larger overvoltage we see a larger slope. 
This $2^{\text {nd }}$ Tafel slope is consistent with the linear sweep results shown in Fig. 14 and with results from the Hall-Héroult process (Thonstad et al., 2001).

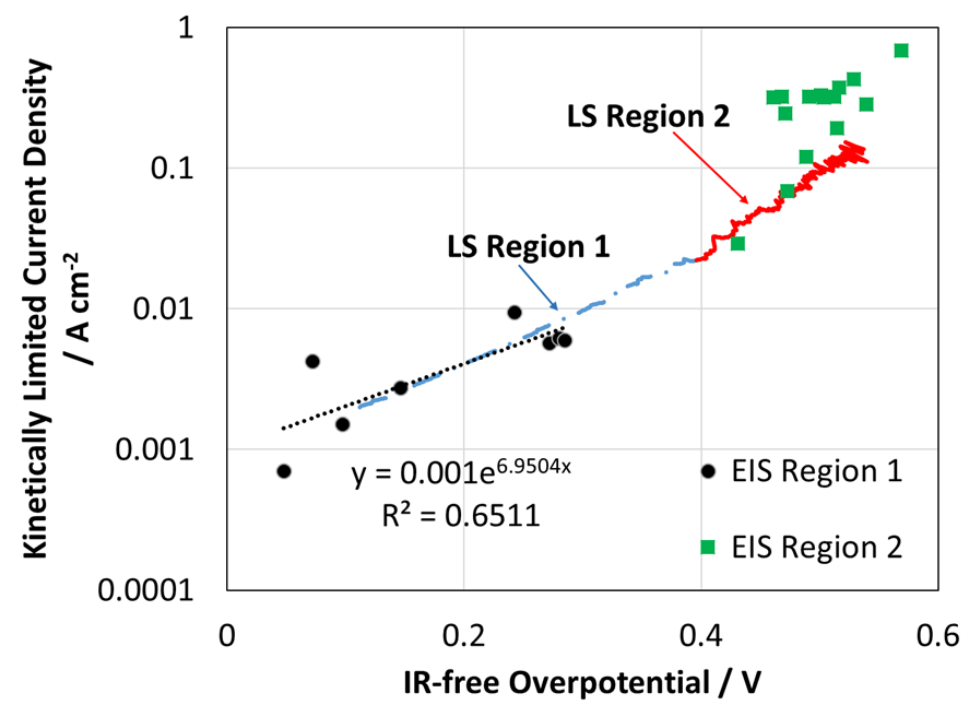

Fig. 18. Kinetically limited current as a function of IR-free overpotential. The calculations based on EIS and LSV observed in molten $\left(\mathrm{MgF}_{2}-\mathrm{CaF}_{2}\right)_{\mathrm{EUT}}-\mathrm{MgO}$ (sat); working electrode: graphite, auxiliary: Mo, reference: Mo.

We believe the larger slope at a high overvoltage is a result of a change in the rate limiting step. Our reasoning for this claim is as follows: the overall charge transfer resistance is a result of two elemental step charge transfer resistances as shown in Equation (20). If these two charge transfer resistances have different Tafel slopes, the relative component of each charge transfer resistance to the total charge transfer resistance would change with overpotential.

For this reason, the first Tafel slope could be explained by $R_{C T, 2}$, and the second Tafel slope could be explained by $R_{C T, 1}$. Theoretically, the first electrochemical step $\left(R_{C T, 1}\right)$ could be rate limiting for the first Tafel slope, but this is unlikely because a slower first charge transfer would decrease surface coverage of an intermediate. Whereas the large 
secondary charge transfer loop suggests that the intermediate surface coverage is extremely high. Furthermore, that intermediate is likely some chemisorbed CO species which is generally a strongly bound species.

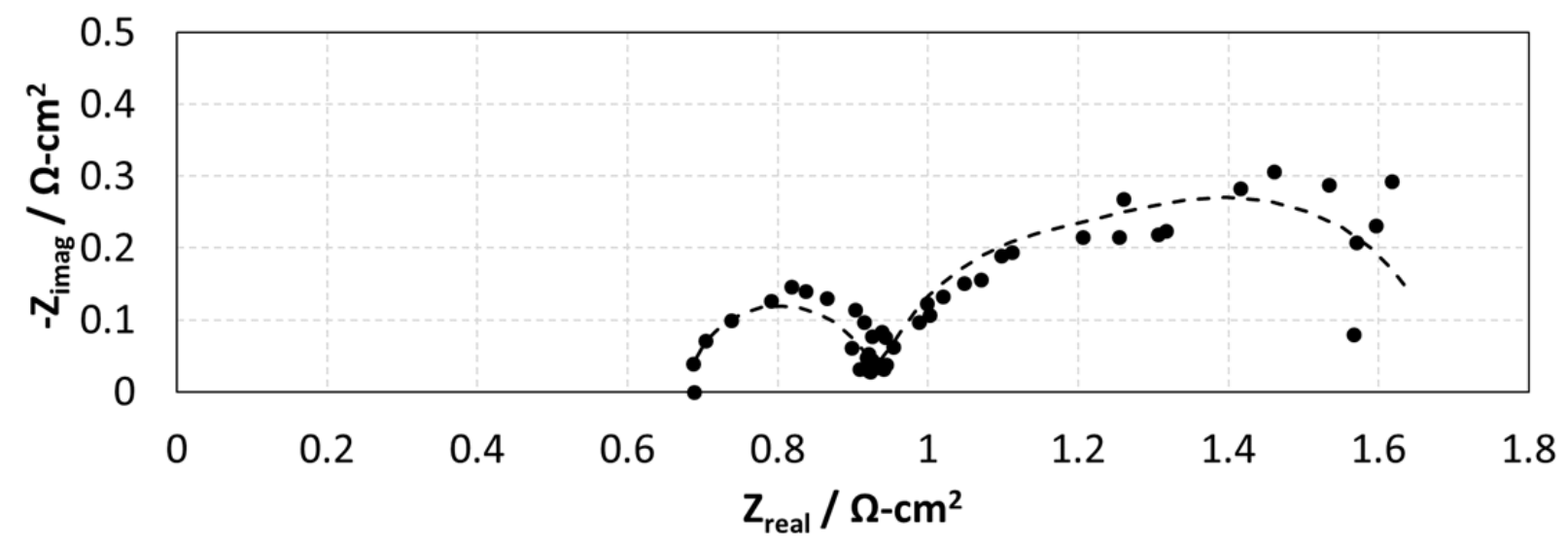

Fig. 19. Characteristic Nyquist plots of an impedance spectrum at a high over potentials $(0.52 \mathrm{~V})$ observed in molten $\left(\mathrm{MgF}_{2}-\mathrm{CaF}_{2}\right)_{\mathrm{EUT}}-\mathrm{MgO}$ (sat); working electrode: graphite, auxiliary: Mo, reference: Mo.

At a higher overvoltage spectra exhibited 45 degree phase angles characteristic of diffusion as shown in Fig. 19. For these spectra, a typical charge transfer loop is followed by an asymmetrical loop. The 45-degree angle on the left side of this loop is a signature of a Warburg diffusional impedance. However, unlike a traditional Warburg impedance which continues at 45 degrees, the impedance spectrum shown in Fig. 19 curves back to the real axis. The return to the real axis is indicative of bounded diffusion.

This type of diffusional impedance is consistent with the theory that bubbling induces mixing at the surface and forms a kinematic boundary layer. The bounded impedance 
Warburg is expressed in Equation (22), and diffusion coefficients and boundary layer thicknesses are calculated from the fit.

Initially the data was fit for both a boundary layer thickness and diffusion coefficient, but the scatter in values was extremely large. None-the-less, in this initial fit, the diffusion coefficient was statistically consistent with the values obtained from cyclic voltammetry and chronoamperometry. In order to reduce that scatter in the calculation of the boundary layer thickness, the spectra were re-fit with a fixed diffusion coefficient based on chronoamperometry $\left(7.2 \mathrm{E}-6 \mathrm{~cm}^{2} \mathrm{~s}^{-1}\right)$. Fig. 20 shows these boundary layer thicknesses as a function of current density.

There is a slight trend towards thinner boundary layers at higher current densities. This suggests that the increased bubbling at higher current densities is decreasing the boundary layer thickness. This being said, the boundary layer thickness is remarkably stable over a large current range, and we can estimate a boundary layer thickness of $4.5 \mathrm{E}-4 \mathrm{~cm}$. This value is in reasonable agreement with the boundary layer thickness of 1.2 E-3 cm reported in Polyakov et al. (1979) for the situation involving bubbling at a carbon anode for a Hall- Héroult cell.

Furthermore, a mass transfer limiting current can be calculated from the expression:

$$
i_{m t}=\frac{n F D c}{\delta}
$$

Using 7.2 E- $6 \mathrm{~cm}^{2} \mathrm{~s}^{-1}$ as a diffusion coefficient and $4.5 \mathrm{E}-4 \mathrm{~cm}$ as a boundary layer thickness, a limiting current of around $3.6 \mathrm{~A} \mathrm{~cm}^{-2}$ can be expected. This value has yet to be verified experimentally, but the high value would suggest that at a reasonable overvoltage diffusion is unlikely to be the primary limiter of cell performance. 


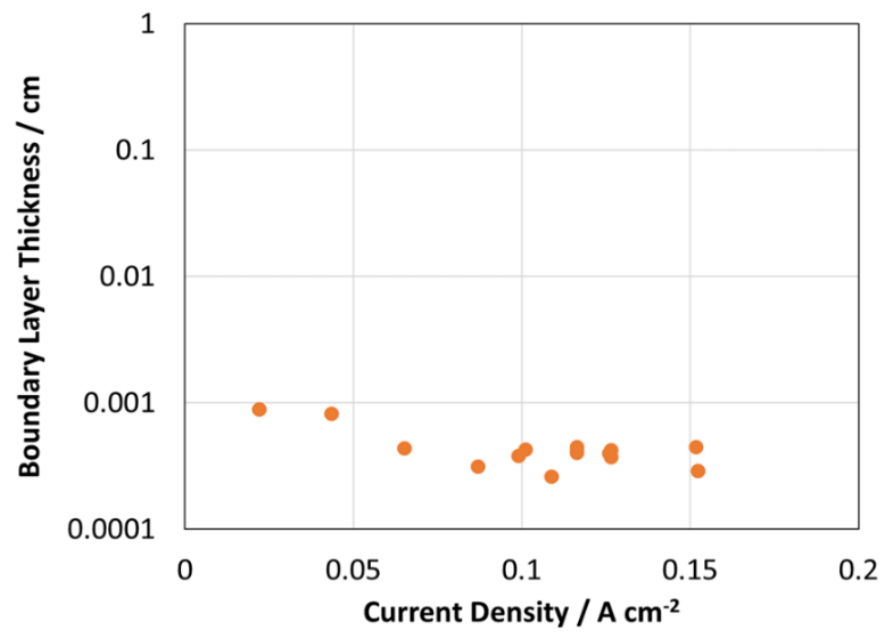

Fig. 20. Boundary layer thickness calculated from EIS as a function of current density. Electrolyte: $\left(\mathrm{MgF}_{2}-\mathrm{CaF}_{2}\right)_{\mathrm{EUT}}-\mathrm{MgO}$ (sat); working electrode: graphite, auxiliary: Mo, reference: Mo.

We have characterized the kinetics and mass transport processes for the anode. A summary of our findings are given in Table 2 .

The best estimate for the exchange current density and transfer coefficient for an overvoltage below $0.4 \mathrm{~V}$ are an average of our LSV and chronoamperometry experiments. The uncertainty interval was chosen to bracket all values. We considered the EIS measurement to be a concomitant check on this value. For the second kinetic region, the LSV values were chosen as our best estimate because they are based on a linear regression of more than 100 points. The EIS values are considered the concomitant check. The uncertainty associated with the regression analysis is not significant compared to the scatter between experimental methods. We thus defined the uncertainty interval such that it contained the values from both methods. 
Table 2. The electrochemical kinetics and mass transport parameters for the anode.

\begin{tabular}{|c|c|c|}
\hline Method & $\boldsymbol{i}_{\mathrm{o}} \mathrm{mA} \mathrm{cm}^{-2}$ & $\boldsymbol{B}$ \\
\hline Linear Sweep & $0.75,0.92\left(\eta_{\text {anode }}<0.4 \mathrm{~V}\right)$ & $0.47,0.59\left(\eta_{\text {anode }}<0.4 \mathrm{~V}\right)$ \\
Voltammetry & $0.14\left(\eta_{\text {anode }}>0.4 \mathrm{~V}\right)$ & $0.71\left(\eta_{\text {anode }}>0.4 \mathrm{~V}\right)$ \\
\hline Chronoamperometry & $0.77\left(\eta_{\text {anode }}<0.4 \mathrm{~V}\right)$ & $0.54\left(\eta_{\text {anode }}<0.4 \mathrm{~V}\right)$ \\
\hline EIS & $1.02\left(\eta_{\text {anode }}<0.4 \mathrm{~V}\right)$ & $0.38\left(\eta_{\text {anode }}<0.4 \mathrm{~V}\right)$ \\
& $0.09\left(\eta_{\text {anode }}>0.4 \mathrm{~V}\right)$ & $0.87\left(\eta_{\text {anode }}>0.4 \mathrm{~V}\right)$ \\
\hline Best Estimate Value & $0.81 \pm 0.21\left(\eta_{\text {anode }}<0.4 \mathrm{~V}\right)$ & $0.5 \pm 0.1\left(\eta_{\text {anode }}<0.4 \mathrm{~V}\right)$ \\
& $0.14 \pm 0.05\left(\eta_{\text {anode }}>0.4 \mathrm{~V}\right)$ & $0.7 \pm 0.2\left(\eta_{\text {anode }}>0.4 \mathrm{~V}\right)$ \\
\hline Method & $\mathbf{D}\left(\mathbf{M g}_{2} \mathbf{O F}_{4}^{2-}\right) \mathbf{c m}^{2}-\mathbf{s}^{-1}$ & $\boldsymbol{\delta} \mathbf{c m}$ \\
\hline Cyclic Voltammetry & $7.0 \mathrm{E}-6$ & $\mathrm{NA}$ \\
\hline Chronoamperometry & $7.2 \mathrm{E}-6$ & $4.5 \mathrm{E}-4$ \\
\hline EIS & $\mathrm{NA}$ & $4.5 \mathrm{E}-4$ \\
\hline Best Estimate Value & $7.2 \pm 0.2 \mathrm{E}-6$ & \\
\hline
\end{tabular}

We also present a summary of the transport parameters associated with the anode reaction. The diffusion coefficient was calculated from both chronoamperometry and cyclic voltammetry. We chose the cyclic voltammetry as a concomitant check because we acknowledge that it is somewhat corrupted by capacitive charging. The uncertainty interval for our best estimate was established as for the cathode. For the diffusion length we do not have sufficient information to define an uncertainty interval. However, as mentioned above, our values are consistent with diffusion lengths calculated for the anode in the Hall-Héroult process. 


\subsection{The Conductance of the Electrolyte}

The uncertainty in the conductance measurements depend to a large extent on the uncertainty of our estimate of the cell constant. It was determined by measuring the impedance of the cell containing pure $\mathrm{NaCl}$ and reconciling the data with the known specific conductivity of $\mathrm{NaCl}$. To complete the certification of the cell, we used it and its cell constant to predict the specific conductivity of $\mathrm{KCl}$. We predicted $\mathrm{KCl}$ conductivity to within $1.6 \%$ of the reported values in the literature (Janz et al. (1979)).

The data of the electrical conductivity are presented as a function of temperature and as a function of the electrolyte composition (Fig. 21). The measured values of electrical conductivity have been formally fit by a least squares second order polynomial regression.

The conductivity of all the measured systems increase with the temperature. The conductivity of the electrolyte without $\mathrm{MgO}$ is $2.9 \mathrm{~S} \mathrm{~cm}^{-1}$ at $1000{ }^{\circ} \mathrm{C}$, which is ca $5 \%$ higher than the conductivity of pure molten cryolite $\left(2.8 \mathrm{~S} \mathrm{~cm}^{-1}\right)-$ the main constituent of the electrolyte in aluminum industry. The curve 3 in the Fig. 21 shows the values of the conductivity in the molten system $\mathrm{MgF}_{2}-\mathrm{CaF}_{2}\left(x\left(\mathrm{MgF}_{2}\right)=55\right.$ mole \%) where the ratio of the $\mathrm{MgF}_{2} / \mathrm{CaF}_{2}$ was shifted from the eutectic mixture toward a slightly higher concentration of $\mathrm{MgF}_{2}$.

A eutectic system of $\mathrm{MgF}_{2}-\mathrm{CaF}_{2}$ with an addition of 0.3 mole $\%$ of $\mathrm{MgO}$ (which is about the solubility of $\mathrm{MgO}$ in this system) leads to a conductivity of $3 \mathrm{~S} \mathrm{~cm}^{-1}$, which is ca $7 \%$ higher than that of pure molten cryolite at the eutectic temperature. However, a further increase of $\mathrm{MgO}$ has a negative influence on the conductivity $\left(2.6 \mathrm{~S} \mathrm{~cm}^{-1}\right)$ of the molten 
fluoride electrolyte. Addition of $\mathrm{MgO}$ beyond the saturation limit likely reduces the conductivity by forming a suspension of $\mathrm{MgO}$ solid particles which impede the current convection paths in the molten electrolyte.

Our results extend the work of others. There are only a few papers dealing with the electrical conductivity of the binary alkaline-earth fluoride systems. Voronin et al. (1980) and Kim and Sadoway (1992) measured electrical conductivity of $\mathrm{SrF}_{2}-\mathrm{MgF}_{2}, \mathrm{BaF}_{2}-$ $\mathrm{MgF}_{2}, \mathrm{CaF}_{2}-\mathrm{MgF}_{2}$ melts, Ogino et al. (1978) measured mixtures of $\mathrm{CaF}_{2}-\mathrm{MgF}_{2}$ and $\mathrm{CaF}_{2}-\mathrm{BaF}_{2}$, Izmolin et al. (2007) measured mixtures of $\mathrm{CaF}_{2}-\mathrm{MgF}_{2}, \mathrm{CaF}_{2}-\mathrm{LiF}$ and $\mathrm{CaF}_{2}-\mathrm{LiF}-\mathrm{NaF}$ and Goncharov et al. (1972) measured the conductivity of the $\mathrm{CaF}_{2}-$ $\mathrm{MgF}_{2}$ system.

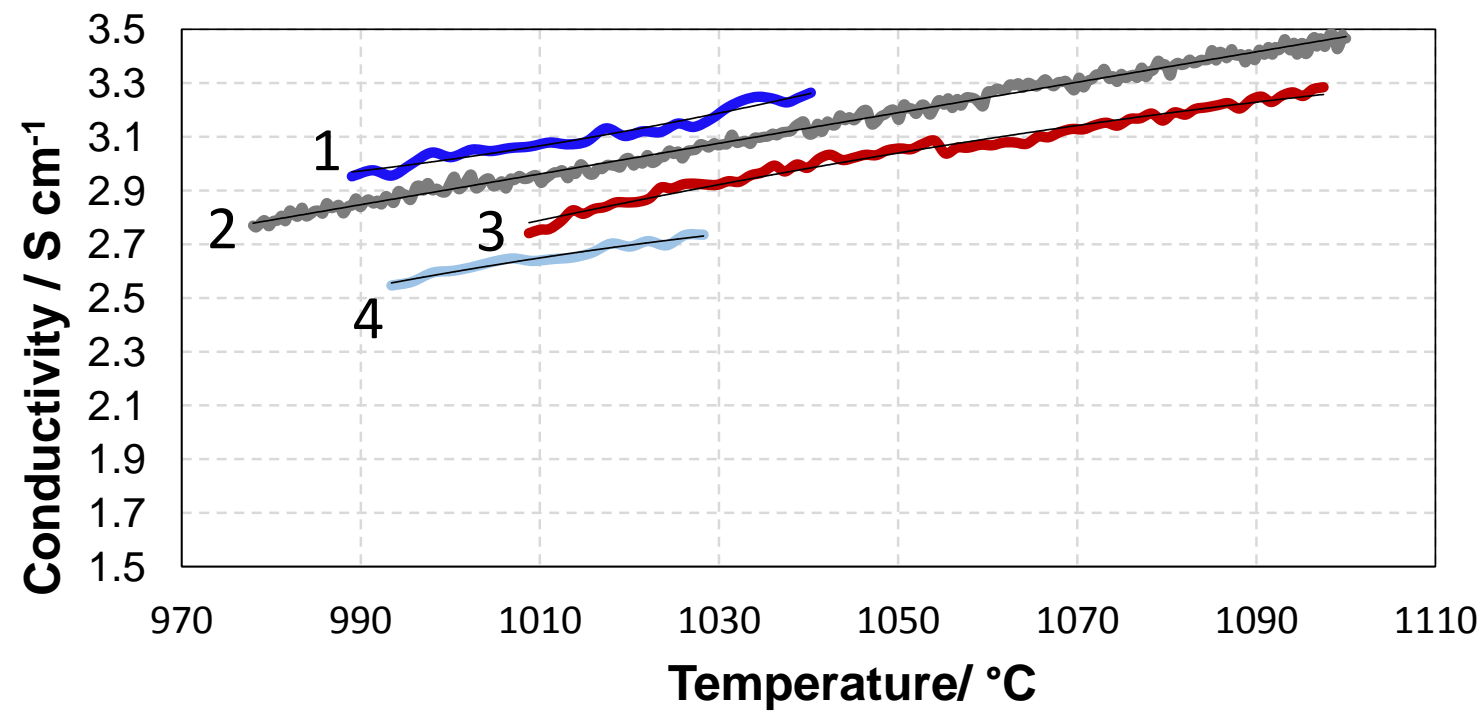

Fig. 21. Conductivity of the molten system $\mathrm{MgF}_{2}-\mathrm{CaF}_{2}-\mathrm{MgO}$ as a function of temperature. (1) - $\left(\mathrm{MgF}_{2}-\mathrm{CaF}_{2}\right)_{\mathrm{EUT}}+0.3$ mole \% MgO; (2) - $\left(\mathrm{MgF}_{2}-\mathrm{CaF}_{2}\right)_{\mathrm{EUT}}$; (3) $\left(\mathrm{MgF}_{2}-\mathrm{CaF}_{2}\right)$ with higher concentration of $\mathrm{MgF}_{2}, x\left(\mathrm{MgF}_{2}\right)=55$ mole \%; (4) - $\left(\mathrm{MgF}_{2}-\right.$ $\left.\mathrm{CaF}_{2}\right)_{\mathrm{EUT}}+1$ mole \% MgO. 
3.7 Combining Electron Transfer Kinetics, Mass Transport, and Electrolyte

Conductance:

\section{A 3D- Finite Element Model of the Cell.}

Using COMSOL 5.2, we modeled a simple cell that could easily be built and tested in the laboratory. The goal was to predict cell current vs. applied potential with the model and compare the model output to experimental data. The degree of the agreement between the model and the experiment serves to further validate our kinetic parameters, diffusion coefficient, and electrolyte conductance.

The crucible for this simple cell was rectangular with the dimensions $13 \mathrm{~cm} \times 7.5 \mathrm{~cm} \times$ $2.54 \mathrm{~cm}$. The electrolyte filled this volume. The anode and cathode rods had areas of $4.0 \mathrm{~cm}^{2}$ and $1.4 \mathrm{~cm}^{2}$ respectively. They were centered in the crucible and $2 \mathrm{~cm}$ apart.

The model couples three physics. Firstly, the potential field satisfies ohms law:

$$
\sigma \nabla^{2} \varphi=0
$$

Equation (29) is applied to three domains; the anode, the cathode, and the electrolyte. $\sigma$ is set to $9.4 \mathrm{E} 4 \mathrm{~S} \mathrm{~cm}^{-1}$ for the electrodes. For the electrolyte it is set to the value we reported above for our electrolyte at $1275 \mathrm{~K}, 2.6 \mathrm{~S} \mathrm{~cm}^{-1}$.

The boundary conditions for Equation (29) are the following: The walls of the crucible and the top of the electrolyte are electrically insulated; the potential at the top of the anode is the applied cell potential; the potential at the top of the cathode is ground. The potentials at the electrode-electrolyte interfaces are coupled to the electrochemical physics describing the electron transfer kinetics through an equation connecting the overvoltage, $\eta$ to the current density, $i$. 
More specifically, the cathode-electrolyte interface potential is coupled to the concentration dependent form of the Butler-Volmer equation for redox Equation (6). In this equation the oxidized species, $c_{0}$, is $\mathrm{Mg}^{2+}$ in solution and the reduced species is $\mathrm{Mg}(\mathrm{I})$. The kinetic and mass transport parameters are our best estimates given in Table1.

Equation (6) is coupled to a third physics, the physics describing mass transfer in a dilute solution:

$$
\frac{\partial C_{o}}{\partial t}=-D_{M g^{2+}} \nabla^{2} C_{o}=J
$$

for $J=0$, accept at the cathode-electrolyte interface, where it is

$$
J=\frac{-i}{n F}
$$

The anode-electrolyte interface potential is described by our Tafel kinetic and mass transport parameters given in Table 2. In Appendix I we show how these parameters lead to the following interface equations.

For an overvoltage less than $0.4 \mathrm{~V}$ :

$$
i=8.1 e-4 \exp \left\langle\frac{0.5 n F}{R T} \eta\right\rangle \mathrm{A} \mathrm{cm}^{-2}
$$

For an overvoltage greater than $0.4 \mathrm{~V}$ we recommend:

$$
i=1.4 e-4 \frac{C^{S}}{C^{B}} \exp \left\langle\frac{0.7 n F}{R T} \eta\right\rangle \mathrm{A} \mathrm{cm}^{-2}
$$


where $\frac{C^{S}}{C^{B}}$ is the ratio of the surface concentration to the bulk concentration:

$$
\frac{C^{s}}{C^{B}}=1-\frac{i}{3.6}
$$

combining equations 30 and 31 , and solving for current density we get:

$$
i=\left[\frac{1}{1.4 e-4 \exp \left(\frac{0.7 n F}{R T} \eta\right)}+\frac{1}{3.6}\right]^{-1} \mathrm{~A} \mathrm{~cm}^{-2}
$$

Furthermore, at all other surfaces, the crucible walls, the top of the electrolyte, and the anode, a zero flux boundary condition is prescribed.

In Fig. 22 we see the agreement between the model and experimental data.

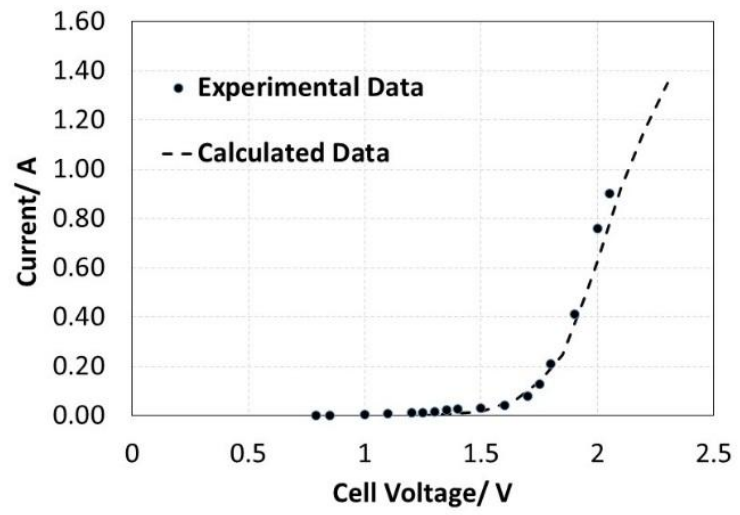

Fig. 22. Validation of the kinetic parameters. The current as a function of the cell voltage. Experiment and calculated data - electrolyte: $\left(\mathrm{MgF}_{2}-\mathrm{CaF}_{2}\right)_{\mathrm{EUT}}-\mathrm{MgO}$ (sat), cathode: Mo, anode: graphite. The calculated data corresponds to a 3-D finite element model of the experimental cell with the established kinetic parameters installed in the governing physics equations. 
At a given cell voltage and the actual current and the calculated one are within $2 \%$ of each other. In short, the results support our argument that we have good estimates of the kinetic and mass transport parameters given in Table 1 and Table 2.

\section{Summary}

We put forward electrochemical reaction mechanisms for our cathode and anode that are consistent with our observations. We quantify the reaction kinetics for both electrodes by estimating their exchange current density and transfer coefficient. We estimate the diffusion coefficients for the electroactive species participating in the cathode and anode reactions. And we have a quantitative estimate of our electrolyte's conductance. In short, we presented the requisite fundamental kinetic and mass transport parameters that enable one to establish the overvoltage needed to obtain a given current density for our electrochemical system.

The overvoltage sets the gap between the amount of energy that must be supplied to drive our reaction and the amount that is electric work. The larger the gap the greater the opportunity (in the words of Dr. Edward Fletcher) to substitute thermal energy for valuable electric work, and the greater the opportunity to reduce operating costs by taking advantage of the lower cost of thermal energy compared to electricity. Based on the results in our finite element model giving the current density vs. overvoltage, the following graph illustrates the opportunity for a thermal input. 


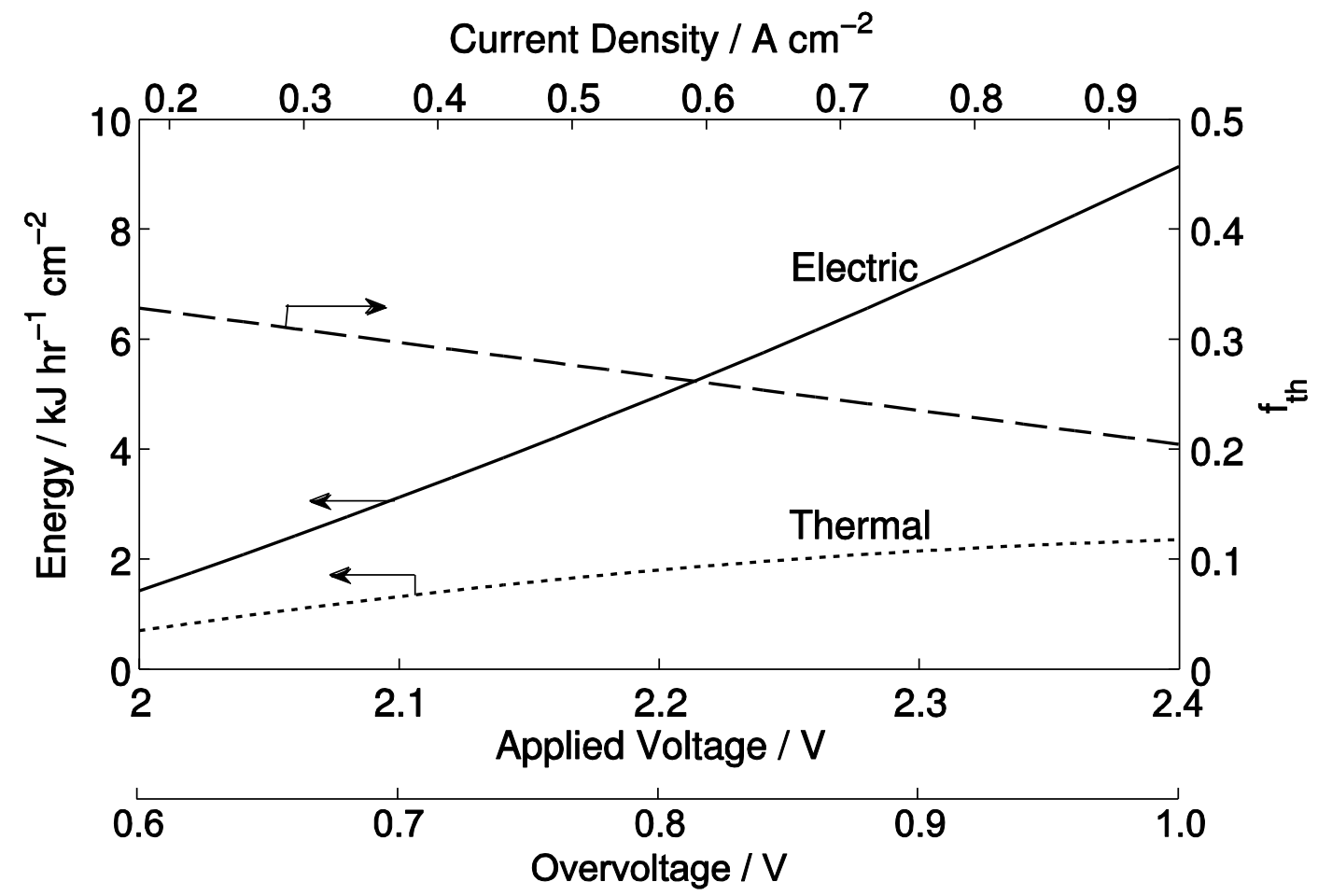

Fig. 23. The area-specific thermal (dotted line) and electric (solid line) energy requirements and the fraction of total energy that is thermal (dashed line) as a function of cell voltage and calculated current density at $1250 \mathrm{~K}$. The current efficiency is assumed to be $90 \%$ and the cell is assumed to be adiabatic.

These results are truly spectacular: For a plant operating with a cell temperature near $1250 \mathrm{~K}$, we show in Fig. 23 that the fraction of thermal input for an adiabatic cell (the values will be higher when one accounts for heat loss) is between $30 \%$ and $20 \%$ for current densities between $0.3 \mathrm{~A} \mathrm{~cm}^{-2}$ and $1 \mathrm{~A} \mathrm{~cm}^{-2}$ respectively. For a cell running at $0.55 \mathrm{~A} \mathrm{~cm}^{-2}$. The cell overvoltage is $0.84 \mathrm{~V}$, with $\eta_{\text {cathode }}=0.05 \mathrm{~V} ; \eta_{\text {anode }}=0.67 \mathrm{~V}, I R=$ $0.12 \mathrm{~V}$.

But some cautionary commentary is required. We consider the cell performance to be our best estimates based on fundamental kinetic and transport process parameters. We have not accounted for IR due to electrical connections, the conductivity of carbon electrodes, and requisite geometry changes to maximize current efficiency. The graph 
thus gives an upper ceiling of what is possible for an adiabatic cell. But because the ceiling is high, we argue it is worth taking on the intellectual and creative challenge of designing a cell that approaches what is fundamentally possible.

In a future article, we will present in detail the fractions of the total energy input that can be thermal from both a technical and an economic perspective; a perspective that reflects our current engineering know-how. Furthermore, we will illustrate how we envision supplying that thermal energy with concentrated sunlight to an electrochemical cell at an industrial scale, illustrating how to do it with laboratory scale concentrated solar energy experiments.

\section{Nomenclature}

$A$ - geometric area of electrode $\left(\mathrm{cm}^{-2}\right)$

a-constant phase exponent, dimensionless

$c_{i}^{B}$ - volumetric concentration of $i$-species in the solution $\left(\mathrm{mol} \mathrm{cm}^{-3}\right)$

$c_{i}{ }^{S}$ - volumetric concentration of $i$-species at the electrode surface $\left(\mathrm{mol} \mathrm{cm}^{-3}\right)$

C - capacitance $\left(\mathrm{F} \mathrm{cm}^{-2}\right)$

$C_{c}-$ constant of the conductivity cell $\left(\mathrm{cm}^{-1}\right)$

$C_{p}$ - capacitance which represents an impact of an adsorbed intermediate on the electrode in the equivalent circuit $\left(\mathrm{F} \mathrm{cm}^{-2}\right)$ 
$C P E_{d l}-$ constant phase angle double layer representing the non-ideal capacitance of the electrode double layer $\left(\mathrm{F} \mathrm{cm}^{-2}\right)$

$D$ - diffusion coefficient $\left(\mathrm{cm}^{2} \mathrm{~s}^{-1}\right)$

$E-\operatorname{potential}(\mathrm{V})$

F- Faraday constant (96 $\left.485 \mathrm{~s} \mathrm{~A} \mathrm{~mol}^{-1}\right)$

$\Delta G_{r x n}-$ change in Gibbs function $\left(\mathrm{kJ} \mathrm{mol}^{-1}\right)$

$\Delta H_{r \times n}$ - enthalpy change $\left(\mathrm{kJ} \mathrm{mol}^{-1}\right)$

$I$ - current $(\mathrm{A})$

$i-$ current density $\left(\mathrm{A} \mathrm{cm}^{-2}\right)$

$i_{0}-$ exchange current density $\left(\mathrm{A} \mathrm{cm}^{-2}\right)$

$i_{K}-$ kinetically limited current density $\left(\mathrm{A} \mathrm{cm}^{-2}\right)$

$i_{M T}-$ mass transfer limiting current density $\left(\mathrm{A} \mathrm{cm}^{-2}\right)$

$j-$ imaginary number, $j=(-1)^{1 / 2}$

$J$-diffusion flux $\left(\mathrm{mol} \mathrm{cm}^{-2} \mathrm{~s}^{-1}\right)$

$k$ - rate constant $\left(\mathrm{cm} \mathrm{s}^{-1}\right)$

$k_{f}-$ rate constant of forward reaction $\left(\mathrm{cm} \mathrm{s}^{-1}\right)$

$k_{r}-$ rate constant of reverse reaction $\left(\mathrm{cm} \mathrm{s}^{-1}\right)$

$L_{\text {sys }}$ - inductance of the system $\left(\mathrm{V} \mathrm{s}^{2} \mathrm{C}^{-1}\right)$

$n$ - number of exchanged electrons, dimensionless 


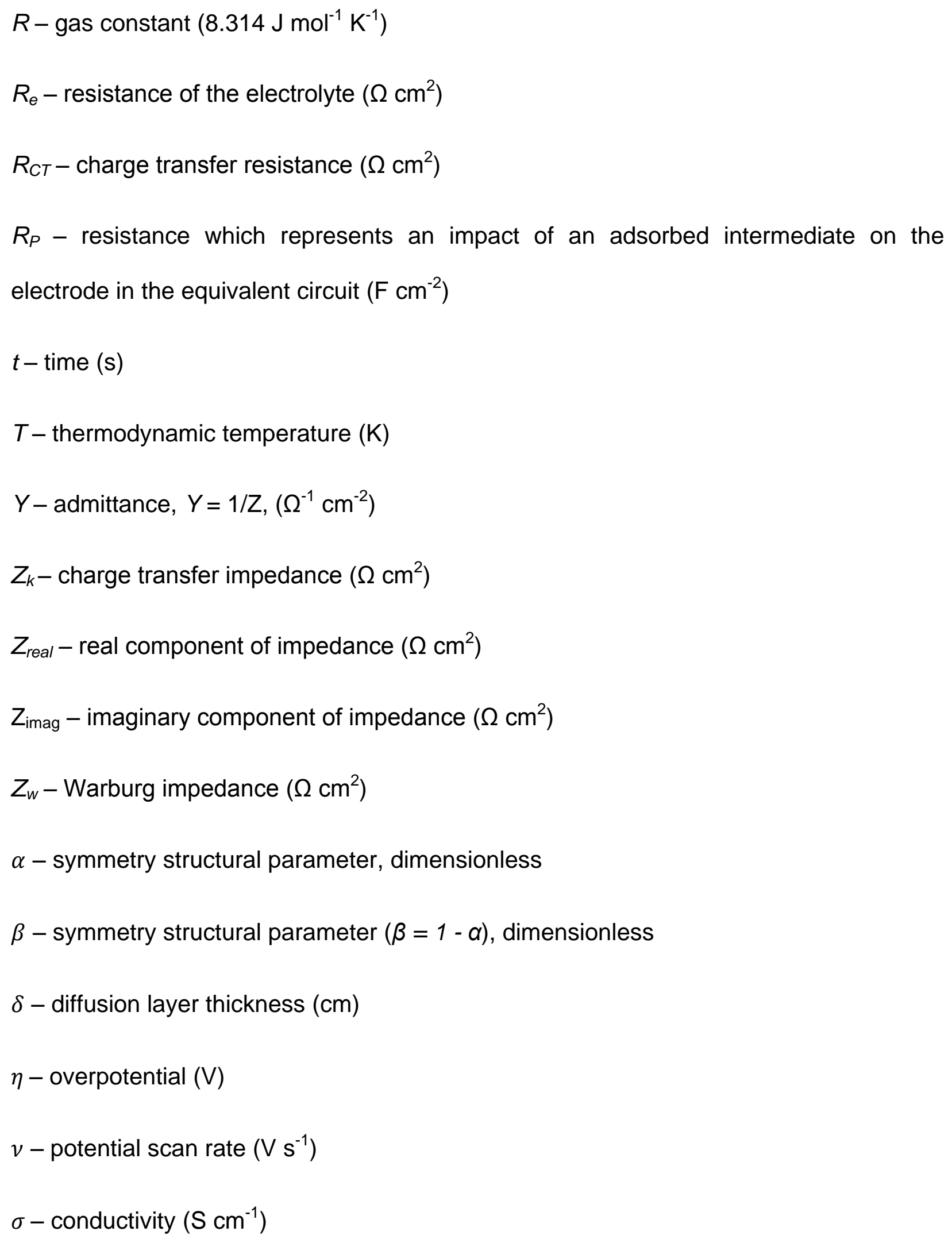


$\tau$ - transition time: time when potential becomes transitioned to higher values during the chronopotentiometry measurement (s)

$\varphi$ - electric potential (V)

$\omega-$ angular frequency, $w=2 \pi f,\left(\mathrm{~s}^{-1}\right)$

\section{Acknowledgements}

We are grateful to the US Department of Energy ARPA-E program for financial support for this work under the cooperative agreement DE-AR0000421. The conductivity part of this work was financially supported by Slovak Grant Agency project VEGA-2/0116/14. We are further grateful to Miroslav Boca (Slovak Academy of Sciences, Bratislava) for his contribution to the conductivity measurement experiments.

We thank E. A. Fletcher for the pioneering work in solar thermal electrochemistry that continues to inspire our work.

\section{References}

Bard, A., Faulkner, L. R., 2001. Electrochemical methods: Fundamentals and Applications. $2^{\text {nd }}$ Edition, John Wiley and Sons, Hoboken.

Barsoukov, E., Macdonald, J. R., 2005. Impedance Spectroscopy Theory, Experiment, and Applications. $2^{\text {nd }}$ Edition, John Wiley and Sons, Hoboken, 494. 
Fletcher, E. A., Noring, J. E., 1983. High temperature solar electrochemical processing Zinc from zinc oxide. Energy - The International Journal. 8(3), 247-254.

Fellner, P., Kobbeltvedt, O., Sterten, Å., Thonstad, J., 1993. Electrical conductivity of molten cryolite-based binary mixtures obtained with a tube-type cell made of pyrolytic boron nitride. Electrochimica Acta. 38, 589-592.

Fletcher, E. A., McDonald, F. J., Kunnerth, D. 1985. High temperature solar electrothermal processing II-Zinc from zinc oxide. Energy - The International Journal. 10(12), 1255-1272.

Goncharov, A. E., Manakov, L. I., Kovalev, P. K., 1972. Surface tension, density, viscosity, and electrical conductivity of calcium fluoride-based fluxes. Trudy Instituta Matallurgii, Akademiya Nauk SSSR. 27, 159-166 (Russ).

Harrington, D. A., Conway, B. E., 2008. AC impedance of faradaic reactions involving electrosorbed intermediates-I. Kinetic theory. Electrochimca Acta. 32, 1703-1712.

Híveš, J., Thonstad, J., Sterten, Å, Fellner, P., 1996. Electrical conductivity of molten cryolite-based mixtures obtained with a tube-type cell made of pyrolytic boron nitride. Metallurgical and Materials Transactions B. 27, 255-261.

Izmolin, S. A., Istomin, V. P., Pastukhov, E. A., Ryabov, V. V., 2007. Physicochemical properties of molten eutectic systems of $\mathrm{CaF}_{2}-\mathrm{MgF}_{2}, \mathrm{CaF}_{2}-\mathrm{LiF}$ and $\mathrm{CaF}_{2}-\mathrm{LiF}-$ NaF. Razplavy. 6, 10-15 (Russ).

Janz, J. G., Allen, B. C., Bansal, N. P., Murphy, R. M., Tomkins, R. P. T., 1979. Physical properties data compilations relevant to energy storage. II. Molten salts: Data 
on single and multi-component salt systems. Washington DC, USA: U.S. Government Printing Office (NSRDS-NBS 61, Part II).

Jarek, S., Thonstad, J., 1987a. Fast voltammetry study of anodic reactions on graphite in cryolite-alumina melts. Electrochimica Acta. 32, 743-747.

Jarek, S., Thonstad, J., 1987b. Voltammetric study of anodic adsorption phenomena on graphite in cryolite-alumina melts. Journal of Electrochemical society. 134, 856-859.

Kim, K. B., Sadoway, D. E., 1992. Electrical conductivity measurements of molten alkaline-earth fluorides. Journal of Electrochemical Society. 139, 1027-1033.

Kisza, A., Kazmierczak, J., Børrensen, B., Haarberg, G. M., Tunold, R. 1993. Kinetics and mechanism of magnesium electrode reaction in molten magnesium chloride. Journal of Applied Electrochemistry. 25, 940-946.

Kisza, A., Kazmierczak, J., Thonstad, J., Eidet, T., Hives, J., 1999. Kinetics and mechanism of electrode reactions in aluminium electrolysis. Light Metals. 423-428.

Korenko, M., Priscak, J, Simko, F., 2013. Electrical conductivity of systems based on $\mathrm{Na}_{3} \mathrm{AlF}_{6}-\mathrm{SiO}_{2}$ melt, Chemical Papers. 67(10),1350-1355 .

Lvovich, V. F., 2012. Impedance spectroscopy: Application to electrochemical and dielectric phenomena. John Wiley and Sons, Hoboken.NIST-JANAF Thermodynamic Tables, [kinetics.nist.gov/janaf/], on-line 9/25/2015.

Ogino, K., Hashimoto, H., Hara, H., 1978. Tetsu To Hagane. 64, 225 (Jap), cited according to Kim and Sadoway (1992). 
Orazem, M. E., Tribollet, B., 2008. Electrochemical Impedance Spectroscopy. John Wiley and Sons, Hoboken.

Palumbo, R., Fletcher, E. A., 1988. High temperature solar electrothermal processing II-Zinc from zinc oxide at 1200-1675K using a Non-Consumable anode. Energy - The International Journal. 13(14), 319-332.

Palumbo, R., Korenko, M., Larson, C., Venstrom, L. J., Duncan, S., Nudehi, S., Schoer, J., Toberman, J., Prusinski, W., Johnson, D., Robinson, B., Barkely, S., Waren, K., Diver, R., Simko, F., Boca, M., 2015. Thermal Electrolytic Production of Mg from MgO: Reflections on Commercial Viability. Magnesium technology, 43-48.

Parks, D. J., Scholl, K. L., Fletcher, E. A., 1988. A study of the use of $\mathrm{Y}_{2} \mathrm{O}_{3}$ doped $\mathrm{ZrO}_{2}$ membranes for solar electrothermal and solar-thermal separations. Energy. 13, 121136.

Polyakov, P. V., Mozhaev, V. M., Burnakin, V. V., Kryukovski, V. A., Nikolaenko V. E., Evolution of bubbles of $\mathrm{CO}_{2}$ gas during electrolysis of cryolite-alumina melts. 1979. Izvestiya Vysshikh Uchebnykh Zavedenii, Tsvetnaya Metallurgiya 1, 55-60 (Russ), cited according to Thonstad et al. (2001).

Thonstad, J., Fellner, P., Haarberg, G. M., Hives, J., Kvande, H., Sterten, A., 2001. Aluminium Electrolysis, Fundamentals of the Hall-Héroult Process, $3^{\text {rd }}$ Edition, Aluminium-Verlag, Düsseldorf.

Voronin, B. M., Prisyazhnyi, V. D., Khizhnyak, K. K., 1980. Equivalent electric coductivity of melts of alkaline earth metal and magnesium fluoride, Ukrainskii Khimicheskii Zhurnal. 46, 584-587 (Russ). 
Wang, X., Peterson, R. D., Tabereaux, A. T., 1992. Electrical conductivity of cryolitic melts. In Proceedings of the $121^{\text {st }}$ TMS Annual Meeting, March 1-5, 1992, The Minerals, Metals \& Materials Society. San Diego, 481-488.

Zhu, H., Thonstad, J., 2003. Anode reaction in aluminum electrolysis prior to and during Anode effect. Light Metals, 343-348.

\section{Appendix I. Kinetic Expression for Anode in Finite Element Model}

As mentioned in the text, the anode interface equation is a combination of kinetic and mass transport parameters. For an overvoltage less than $0.4 \mathrm{~V}$, the surface concentration matches the bulk concentration. For this reason a simple Tafel expression like Equation 9 is used:

$$
i=8.1 e-4 \exp \left\langle\frac{0.5 n F}{R T} \eta\right\rangle \mathrm{A} \mathrm{cm}^{-2}
$$

Here the values from Table have been substituted into the equation. For an overvoltage greater that $0.4 \mathrm{~V}$ we recommend this concentration dependent form of the Tafel Equation:

$$
i=1.4 e-4 \frac{C^{S}}{C^{B}} \exp \left\langle\frac{0.7 n F}{R T} \eta\right\rangle \mathrm{A} \mathrm{cm}^{-2}
$$


Note that the kinetic parameters have changed to the second region values in Table 3. In this equation, $\frac{C^{S}}{C^{B}}$ is the ratio of the surface concentration to the bulk concentration. This ratio can be established via the mass transfer limiting current from Equation 28. As the current approaches the mass transfer limiting current, the current and surface concentration are related by the following equation:

$$
i=\frac{n F D\left(c^{B}-c^{S}\right)}{\delta}
$$

By rearranging this equation and substituting into Equation (28) (the mass transfer limiting current) the surface concentration is:

$$
\frac{c^{s}}{c^{B}}=1-\frac{i}{i_{m t}}
$$

Combining Equations (AI.2) and (AI.4) and inserting 3.6 for the mass transport limiting current we get:

$$
i=1.4 e-4\left(1-\frac{i}{3.6}\right) \exp \left\langle\frac{0.7 n F}{R T} \eta\right\rangle \mathrm{A} \mathrm{cm}^{-2}
$$

Solving for current density we get:

$$
i=\left[\frac{1}{1.4 e-4 \exp \left(\frac{0.7 n F}{R T} \eta\right\rangle}+\frac{1}{3.6}\right]^{-1} \mathrm{~A} \mathrm{~cm}^{-2}
$$

This equation represents the total anode interface equation, including mass transport, for an overvoltage greater than $0.4 \mathrm{~V}$. 